\title{
Intertemporal pro-poorness
}

\section{Florent Bresson ${ }^{1}$ • Jean-Yves Duclos ${ }^{2}$. Flaviana Palmisano ${ }^{3}$}

Received: 2 October 2015 / Accepted: 18 June 2018

(c) Springer-Verlag GmbH Germany, part of Springer Nature 2018

\begin{abstract}
A long-lasting scientific and policy debate queries the impact of growth on distribution. A specific branch of the micro-oriented literature, known as 'pro-poor growth', seeks in particular to understand the impact of growth on poverty. Much of that literature supposes that the distributional impact should be measured in an anonymous fashion. The income dynamics and mobility impacts of growth are thus ignored. The paper extends this framework in two important manners. First, the paper uses an 'intertemporal pro-poorness' formulation that accounts separately for anonymous and mobility growth impacts. Second, the paper's treatment of mobility encompasses both the benefit of "mobility as equalizer" and the variability cost of poverty transiency. Several decompositions are proposed to measure the importance of each of these impacts of growth on the pro-poorness of distributional changes. The framework is applied to panel data on 23 European countries drawn from the 'European Union Statistics on Income and Living Conditions' survey.
\end{abstract}

\section{Introduction}

A long-lasting micro/macro-economic question of interest addresses the dynamic relationship between growth and distribution. There is, in particular, a specific branch of the micro-oriented literature, known as 'pro-poor growth', that is generating continuous attention both scientifically and policy-wise, with the main objective of assessing the extent to which poverty changes over time because of growth. A number of differ-

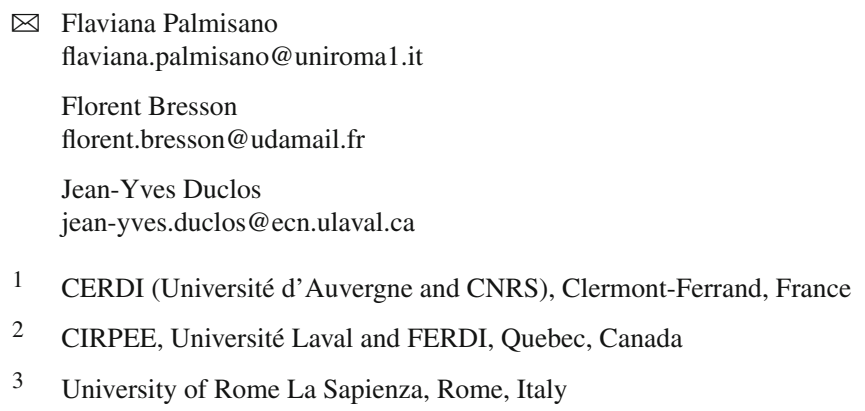


ent analytical tools have been developed in the associated pro-poor growth literature for that purpose (see, inter alia, Ravallion and Chen 2003; Son 2004; Essama-Nssah 2005; Essama-Nssah and Lambert 2009; Duclos 2009).

A common feature of these tools is that the identity of the growth beneficiaries is irrelevant to the analysis; that is, the analytical tools satisfy an 'anonymity' property. Anonymity is a standard property for the measurement of poverty and inequality, requiring that distributive measures be invariant to a permutation of individual income vectors. This is an often uncontroversial assumption and is in particular perfectly agreeable if the aim is to understand the purely cross-sectional effect of growth. But postulating anonymity implies that income dynamics are ignored, namely that the mobility experience taking place because of growth is not of normative and measurement interest.

To see this better, consider the following two separate transformations $A$ and $B$, from one time period to another, undergone by a distribution of income of four individuals:

$$
\begin{aligned}
& (4,6,9,9) \underset{A}{\rightarrow}(9,9,4,6), \\
& (4,6,9,9) \underset{B}{\rightarrow}(4,6,9,9),
\end{aligned}
$$

and assume that the poverty line is fixed to 7 in both periods. A common procedure to evaluate the pro-poorness of such income transformations is to compute the Rate of Pro-Poor Growth (RPPG, Ravallion and Chen 2003), which would be equal to 0 for transformation $A$ as the final marginal distribution of income is strictly identical to the initial marginal distribution. This would be true for all other measures of pro-poorness that can be expressed as functions of poverty separately in each single period of time. ${ }^{1}$ The RPPG would also be equal to 0 for the transformation $B$. The income dynamics otherwise implied by $A$ and $B$ are, however, quite different: $A$ leads to considerable mobility whereas $B$ does not and we may therefore wish their degree of pro-poorness to differ.

Because of this, recent contributions have argued that pro-poor and welfare judgments of the effect of growth should be based on a 'non-anonymous' perspective (see notably Grimm 2007; Jenkins and Van Kerm 2011; Bourguignon 2011; Palmisano and Peragine 2015; Palmisano and Van de gaer 2016). Proponents of this emphasize the role played by mobility in the distributional effects of growth. While both the measurement of growth pro-poorness and the measurement of mobility are quite developed (see for instance Fields and Ok 1999; Fields 2008; Jäntti and Jenkins 2015, for significant reviews), the analysis of the impact of mobility on growth pro-poorness is yet to be developed to our knowledge, notably because the proposed tools generally do not consider poverty from an intertemporal point of view. For instance, Grimm (2007) proposes an Individual Rate of Pro-Poor Growth that specifically focuses on the impact of growth on the initially poor and ignores the negative income effects of those who experience deprivation after growth. Foster and Rothbaum (2012) use cutoff-based mobility measures to explain variations of poverty over time. However,

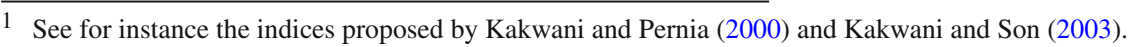


their method only applies to two specific indices measuring snapshot poverty, namely the headcount ratio and the average poverty gap.

This paper's approach is both conceptually and methodologically different from previous contributions on the topic. Considering the individual poverty trajectories over time, we explicitly take various mobility effects into account. On the one hand, in line with Friedman (1962), we let growth pro-poorness be sensitive to the equalization effect of mobility on the distribution of permanent incomes. On the other hand, we also let growth pro-poorness depend on the variability cost introduced by mobility, since time variability may reduce welfare if individuals are risk averse. Whether growth is pro-poor is then determined by comparing observed intertemporal poverty with a benchmark consisting of the absence of any kind of distributional change.

Our measurement framework draws from Bibi et al. (2014), who measure the welfare implication of mobility accounting for the cost of inequality accross time and accross individuals. However, their contribution is silent on the impact of growth and mobility on poverty (see also Gottschalk and Spolaore 2002; Creedy and Wilhelm 2002; Makdissi and Wodon 2003).

This paper further explores various pro-poorness features of growth through a set of additive decompositions. The first decomposition separates the measurement of anonymous growth from that of non-anonymous growth. The second decomposition disentangles the contribution of changes in inequality, reranking and pure growth in explaining the pro-poorness of growth. Finally, a third decomposition makes it possible to estimate the contribution of each subperiod to intertemporal pro-poorness.

The paper concludes with an empirical illustration of the measurement framework for 23 European countries during the period 2006-2009. The results show that the 2006-2009 period can be judged to be pro-poor in most European countries. However, the intertemporal pro-poorness features of the income transformations vary considerably across European countries and within each country, depending on the interplay between intertemporal poverty variability versus inter-individual inequality. Thus, our results show that mobility, through its costs and benefits, can play a relevant role in the assessment of growth pro-poorness and can provide useful information in the evaluation of the impact of growth on poverty.

The contribution of this paper is thus twofold. The first is to account for the impact of an income transformation on intertemporal poverty and, in so doing, to disentangle the impact of anonymous growth from the impact of mobility (or non-anonymous growth). The second contribution is to extend the "mobility as equalizer" framework to take into account the impact of mobility on poverty, corrected for the cost of poverty transiency as well as the cost of inequality in the distribution of intertemporal poverty.

The rest of the paper is organized as follows. Section 2 introduces the conceptual framework. Section 3 proposes a family of indices of intertemporal pro-poorness. Section 4 presents a set of additive decompositions for the proposed indices. An empirical illustration of this framework is contained in Sect. 5. Section 6 concludes. 


\section{General measurement of pro-poorness in an intertemporal setting}

Assume that we are interested in the dynamics of a distribution of living standards (incomes, for short) and ill-fare of $n \in \mathfrak{N}$ individuals, with individuals denoted $i=1, \ldots, n$ over $T \in \mathfrak{N} \backslash\{1\}$ fixed time periods (annual or monthly for instance) of their life and with each generic period denoted by $t=1, \ldots, T$. We assume $T$ to be common to all individuals, viz, we are comparing people's lives over the same number of time periods.

We assume periodic income $y_{i, t}$ to be drawn from the set of non-negative real numbers $\Re_{+}$. Let $\boldsymbol{y}_{(i)}:=\left(y_{i, 1}, \ldots, y_{i, t}, \ldots, y_{i, T}\right)$ then be the vector of individual $i$ 's incomes across the $T$ periods and $\boldsymbol{y}_{t}$ be a cross-sectional vector of incomes at time $t$. The income profile $\boldsymbol{y}_{(i)}$ is the $i$ th row of the $n \times T$ matrix $\boldsymbol{Y} \in \boldsymbol{\Omega}^{n, T}$, where $\boldsymbol{\Omega}^{n, T}$ is the set of all $n \times T$ matrices whose entries are non-negative real numbers. We assume that incomes have been normalized by the poverty line $z_{t} \in \mathfrak{R}_{++}$-which could be absolute (constant in real terms) or relative (to income norms that vary across time). Let then $\tilde{y}_{i, t}:=\min \left(y_{i, t}, 1\right)$ be the periodic income censored at the corresponding poverty line. Over an individual's lifetime, poverty is measured by $p\left(\boldsymbol{y}_{(i)}\right)$ with $p\left(\boldsymbol{y}_{(i)}\right) \geq 0$ whenever $\exists t \in\{1, \ldots, T\}$ such that $y_{i, t}<1$ and $p\left(\boldsymbol{y}_{(i)}\right)=0$ otherwise. Total intertemporal poverty is measured by the index $P(\boldsymbol{Y})$.

In the traditional context of snapshot poverty analyses, testing the pro-poorness of a growth process implies comparing the observed final poverty level with the one observed under some given benchmark. Such a benchmark could be either a desirable final level of poverty or a counterfactual one; denote it by $\hat{\boldsymbol{Y}}$.

Our own measurement of pro-poor growth is anchored in the intertemporal propoorness evaluation function $\operatorname{IPP}(P(\hat{\boldsymbol{Y}}), P(\boldsymbol{Y}))$ where $P(\hat{\boldsymbol{Y}})$ is benchmark poverty. We require that the measure of pro-poor growth be increasing in $P(\boldsymbol{Y})$, decreasing in $P(\hat{\boldsymbol{Y}})$, and equal to zero if there is no difference between poverty in the actual and in the benchmark distributions. ${ }^{2}$ A broad class of measures would be consistent with these requirements. For expositional simplicity, we take the simple linear form:

$$
\operatorname{IPP}(P(\hat{\boldsymbol{Y}}), P(\boldsymbol{Y})):=P(\hat{\boldsymbol{Y}})-P(\boldsymbol{Y})
$$

The definition of the benchmark situation is crucial as different benchmark distributions will naturally lead to different evaluations of growth pro-poorness. The choice depends mainly on whether a relative or an absolute approach is taken to evaluate propoorness - the former approach stating that growth is pro-poor when the incomes of the poor grow faster than some norm (often proportional to average or mean income) and the latter stating that growth is pro-poor when the incomes of the poor are growing absolutely speaking. For expositional simplicity, this paper follows an absolute approach, although generalizing to a relative approach would just mean that incomes would need to be divided by the norm (possibly by a simple adjustment of the poverty line).

Similarly, we must also agree on a concept of mobility. 'Mobility means different things to different people,' in the words of Fields (2008, p. 1). Here, we interpret

\footnotetext{
2 See on this Fields (2010).
} 
mobility as any temporal change in individual income. A natural candidate for the benchmark is thus the absence of distributional changes. The benchmark is therefore a counterfactual income distribution $\boldsymbol{Y}_{1} \in \boldsymbol{\Omega}^{n, T}$ in which every person's income is the same as that person's income in the first period. ${ }^{3}$

The index $\operatorname{IPP}(P(\hat{\boldsymbol{Y}}), P(\boldsymbol{Y}))$ in (3) is then the difference between poverty in a counterfactual situation in which poverty in the first period is extended over the $T$-period horizon and observed intertemporal poverty. ${ }^{4}$

As known in the growth pro-poorness literature (Duclos 2009), rival versions can be proposed for the construction of the counterfactual distribution. For instance, the nomobility counterfactual distribution could refer to the absence of exchange mobility, hence resulting in a counterfactual distribution showing the same marginal distributions as the observed distribution but without reranking from year to year. Another possibility would be to take a relative view, that is, to consider a 'neutral' growth process (in terms of snapshot inequality) over the studied period. ${ }^{5}$ The use of a counterfactual different from the first period distribution would, however, imply a different interpretation of the IPP index and could lead to a set of decompositions different from those proposed in the following sections.

\section{A family of intertemporal pro-poorness indices}

\subsection{Individual ill-fare}

Let the (normalized) poverty gaps be given by $g_{i, t}:=1-\tilde{y}_{i, t}$, let $\boldsymbol{g}_{(i)}:=\left(g_{i, 1}, \ldots, g_{i, t}, \ldots, g_{i, T}\right)$ be the corresponding vector of normalized poverty gaps for individual $i$ across $T$ periods, and let $\boldsymbol{G}$ be the corresponding $n \times T$ matrix of normalized poverty gaps for the whole population. Also, let the distribution of gaps at time $t$ be given by the vector $g_{t}:=\left(g_{1, t}, \ldots, g_{n, t}\right)$. The gap $g_{i, t} \in[0,1]$ is a standard measure of individual poverty in the literature for both snapshot and intertemporal poverty measurement. ${ }^{6}$ It is, for instance, the basis of the well-known FGT class (Foster et al. 1984) of additive poverty indices as well as of its intertemporal generalizations in Foster (2009), Canto et al. (2012) or Busetta and Mendola (2012),

3 This is consistent with the approach used in Chakravarty et al. (1985) and Fields (2010), although the benchmark in Chakravarty et al. (1985) is based on relative immobility, i.e. the share of each individual in total income is assumed to remain stable across time.

4 This property is called normalization in Hoy and Zheng (2011), requiring that if an individual gets every period the same income level, then his lifetime poverty can be represented by snapshot poverty.

5 As mentioned by an anonymous referee, a possible issue related to our choice of the counterfactual distribution is that the initial period could be 'abnormal' compared to the following periods, hence resulting in large values of the $I P P$, in particular if $T$ is relatively large. A possible fix could be to test the sensitivity of the results by considering a contiguous year as the reference year, or averaging individual incomes for the first years of the growth spell.

6 Recent contributions, like Dutta et al. (2013), Zheng (2012) or Jäntti et al. (2014), have investigated the role of affluence in intertemporal poverty measurement. The core idea is that, up to some threshold, affluence at a certain date could compensate for past or future deprivation. In this paper's perspective, this could be done by assuming $g_{i t} \in[a, 1]$ with $a \leq 0$ and possibly introducing slight changes in the definition of the indices introduced in this section such as to avoid odd consequences (e.g., having $p_{\beta}>0$ for non poor person or excessively mitigating affluence effects). 
not to mention specific members of the family of indices introduced by Hoy and Zheng (2011), Bossert et al. (2012) and Dutta et al. (2013).

In order to account explicitly for the cost of time variability, we use the poverty counterpart of the 'equally distributed equivalent income' introduced in Atkinson (1970) for the measurement of social welfare and inequality. The equally distributed equivalent (EDE) poverty gap for individual $i, \pi_{\beta i}$, is given by:

$$
\pi_{\beta i}:=p\left(\boldsymbol{y}_{(i)}\right)=\left(\sum_{t=1}^{T} \omega_{t} g_{i, t}^{\beta}\right)^{\frac{1}{\beta}}
$$

The EDE gap $\pi_{\beta i}$ is the value of the gap that, if experienced at each period of $i$ 's lifetime, would yield $i$ the same level of poverty over time as that generated by $\boldsymbol{g}_{(i)} \cdot \omega_{t}>0, t \in\{1, \ldots T\}$, forms a set of weights that capture the sensitivity of poverty to the specific period in which deprivation is experienced and such that, for normalization purposes, $\sum_{t=1}^{T} \omega_{t}=1$. $^{7}$ If $\omega_{t}>\omega_{t+1}$, more importance is given to poverty experienced earlier in the time horizon considered, for instance in childhood; if $\omega_{t}<\omega_{t+1}$, more importance is given to poverty experienced later in the time horizon considered. The weights $\omega_{t}$ can also be interpreted as discount rates expressing a judgment on the importance of poverty suffered in the present relative to poverty suffered in the future. Many contributions in the economic literature evaluate the flow of a given variable by imposing discount rates that give earlier elements higher importance-corresponding to decreasing values of $\omega_{t}$ in our framework. This choice, though perfectly legitimate, is not the only one possible and may not be supported by normative reasoning. In other words, it is normatively unclear whether to give priority to poverty experienced earlier nearby as compared to poverty experienced later on. Discounting the future more can be justified by the belief that low income earlier in life may impact the standards of living later in life more than the other way around. However, in evaluating poverty profiles, it may also be argued that gradually drifting into poverty is worse than evolving from spells in poverty out of poverty, even if the number and the depth of spells in poverty may be similar in both cases. ${ }^{8}$

The parameter $\beta$ is a measure of aversion to variability in the poverty gaps. Higher levels of $\beta$ give higher weights to a loss of income when income is already low than when it is large. For $\beta=1$, Eq. (4) corresponds to the simple weighted average of $i$ 's poverty gaps across time. For $\beta>1$, a sequence of income increments and decrements that keep the weighted mean of the gaps unchanged but reduces their intertemporal variability decreases $\pi_{\beta i}$. Equation (4) is a measure of "union" poverty since individuals are regarded as intertemporally poor whenever they are deprived during at least one time period. ${ }^{9}$

\footnotetext{
7 Having weights that sum to one is not necessary to obtain a consistent poverty pre-order. However, slackening this constraint would not make it possible to interpret $\pi_{\beta i}$ as an individual EDE gap.

8 See on this Hoy and Zheng (2011), Calvo and Dercon (2009), and Bresson and Duclos (2015).

9 A generalization with other definitions of the poverty domain using a counting approach à la Alkire and Foster (2011) can be performed by censoring the vector $\boldsymbol{g}_{(i)}$ when the (weighted) number of deprivations is less than a given threshold $\in] 1, T]$.
} 
Hence, for $\beta \geq 1, \pi_{\beta i}$ is never lower than $\pi_{1 i}$ because of aversion to poverty variability. The difference can be interpreted as the cost of deprivation variability for individual $i$ :

$$
c_{\beta i}:=\pi_{\beta i}-\pi_{1 i} .
$$

Consequently, intertemporal poverty for $i$ can be expressed as:

$$
\pi_{\beta i}=c_{\beta i}+\pi_{1 i}
$$

Hence, $\pi_{\beta i}$ is (weighted) average intertemporal poverty plus the intertemporal cost of mobility.

\subsection{Social ill-fare}

The next step is to aggregate individual EDE gaps in order to obtain a socially representative measure of poverty. As with traditional snapshot poverty, many functional forms can be proposed to perform this social aggregation. Here, the EDE formulation is also used to aggregate individual poverty. Social ill-fare is then given by ${ }^{10}$ :

$$
\Pi_{\alpha, \beta}(\boldsymbol{G}):=\left(\frac{1}{n} \sum_{i=1}^{n}\left(\pi_{\beta i}\right)^{\alpha}\right)^{\frac{1}{\alpha}}
$$

where $\alpha \geq 0$ is a parameter of aversion to poverty inequality across individuals. An anonymous evaluation of intertemporal poverty can be performed using $\Pi_{\alpha, 1}$ : switching the income of two poor individuals at a given period $t$ then leaves the social evaluation of intertemporal poverty unchanged, whatever the income levels of the two individuals in the other periods. ${ }^{11}$

$\Pi_{\alpha, \beta}(\boldsymbol{G})$ can be usefully interpreted as the level of the poverty gap which, if assigned equally to all individuals and across all time periods, would produce the same poverty level as that generated by the intertemporal distribution $\boldsymbol{G}$. It thus can be seen as an intertemporal generalization of the class of ethical poverty indices introduced by Chakravarty (1983a) for snapshot monetary poverty. Since the index aggregates individuals' intertemporal poverty, it also incorporates early/late poverty sensitivity with weights $w_{t}$ and parameter $\beta$. Furthermore, as $\pi_{\beta}$ is a generalized mean of snapshot

$\overline{10}$ Using for instance Chakravarty's (1983b) aggregation formula, we obtain the alternative intertemporal poverty index $P_{\beta, \delta}^{\prime}$ :

$P_{\beta, \delta}^{\prime}:=\frac{1}{n} \sum_{i=1}^{n} 1-\left(1-\pi_{\beta i}\right)^{\delta}$,

with $\delta \in] 0,1]$. The corresponding $\operatorname{EDE}$ gap $\Pi_{\delta, \beta}^{\prime}$ is then:

$\Pi_{\beta, \delta}^{\prime}:=1-\left(1-\frac{1}{n} \sum_{i=1}^{n} 1-\left(1-\pi_{\beta i}\right)^{\delta}\right)^{\frac{1}{\delta}}$.

11 This can be more easily seen if we express $\Pi_{\alpha, a}(\boldsymbol{G})$ as:

$\Pi_{\alpha}(\boldsymbol{G})=\left(\sum_{t=1}^{T} \omega_{t} \frac{1}{n} \sum_{i=1}^{n} g_{i, t}^{\alpha}\right)^{\frac{1}{\alpha}}=\left(\sum_{t=1}^{T} \omega_{t} P_{\alpha}\left(\boldsymbol{g}_{t}\right)\right)^{\frac{1}{\alpha}}$. 


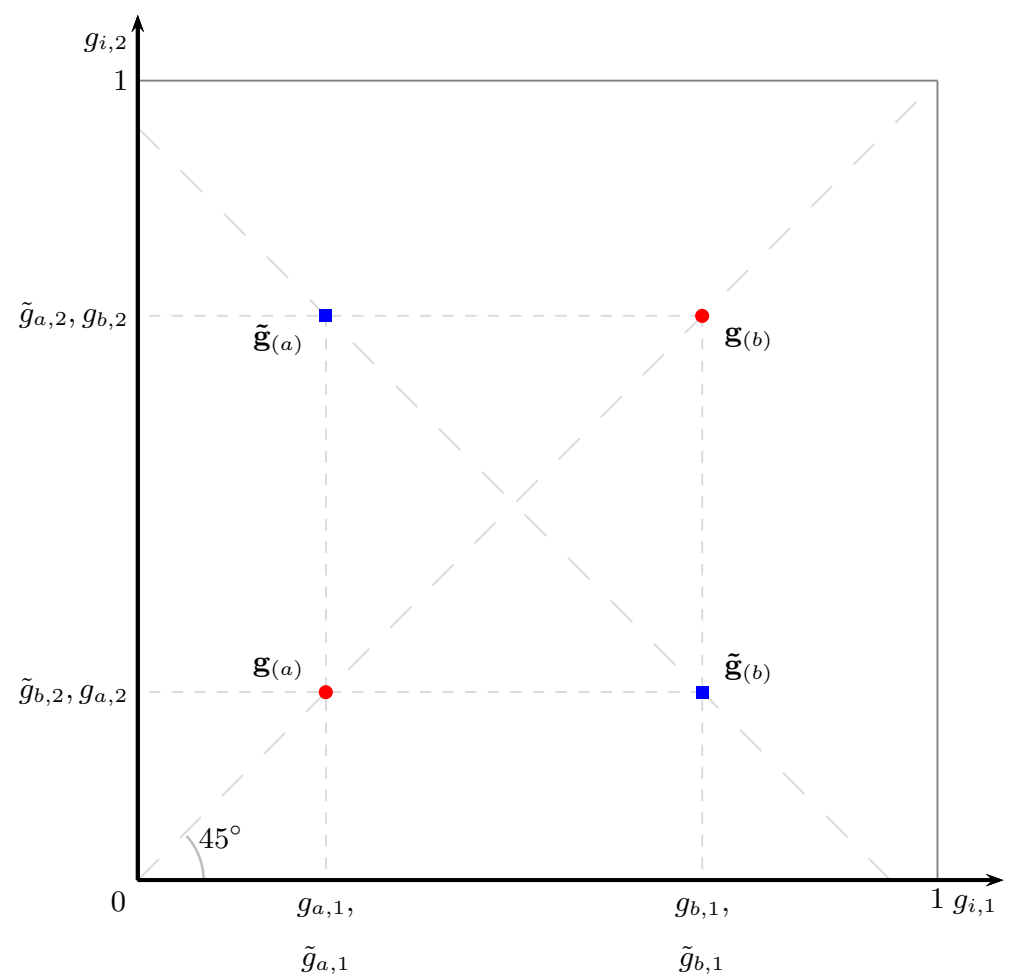

Fig. 1 Inter-individual inequality vs intertemporal variability

income gaps at the individual level, $\Pi_{\alpha, \beta}(\boldsymbol{G})$ is a generalized weighted mean of equally distributed equivalent poverty gaps $\left(\pi_{\beta}\right)$.

Figure 1 helps understand the trade-off between gap inequality and gap variability and its implications for pro-poor evaluation. It shows the poverty gap of two individuals, $i=a, b$, over a two-period lifetime horizon, $t=1,2$, in two different polar cases. For the sake of clarity, we assume that $\omega_{1}=\omega_{2}$. In the first case with the circular dots, the two individuals experience identical poverty each period, that is, $g_{a, 1}=g_{a, 2}=\pi_{\beta a}$ and $g_{b, 1}=g_{b, 2}=\pi_{\beta b}$, but there is inequality of poverty between them. Thus $\Pi_{\alpha, \beta}(\boldsymbol{G})=\Pi_{\alpha}\left(g_{1}\right)$. The second case with the square dots is the reverse one: $\tilde{g}_{a, 1}=\tilde{g}_{b, 2} \neq \tilde{g}_{b, 1}=\tilde{g}_{a, 2}$, and $\tilde{\pi}_{\beta a}=\tilde{\pi}_{\beta b}=\Pi_{\alpha, \beta}(\tilde{\boldsymbol{G}})$, namely, the two individuals have the same overall distribution of poverty gaps but experience different levels of poverty at different time periods.

The poverty ranking of these two distributions will depend on social aversion towards poverty variability and poverty inequality. Note that the distribution of periodic poverty gaps is the same under the two processes. With the same degree of aversion towards variability and inequality (i.e. $\alpha=\beta$ ), the two distributions are judged equivalent in terms of poverty. This happens because, in the first case, there are neither costs nor benefits generated by mobility, whereas, in the second case, the benefits of intertemporal poverty equalization are canceled out by the costs of variability. 
Indifference towards variability, $\beta=1$, makes $\tilde{\boldsymbol{G}}$ no worse than $\boldsymbol{G}$, while indifference towards inequality $(\alpha=1)$ makes $\boldsymbol{G}$ no worse than $\tilde{\boldsymbol{G}}$. Hence, whether $\boldsymbol{G}$ has more poverty than $\tilde{\boldsymbol{G}}$ will depend on the values of $\alpha$ and $\beta$.

One can notice that $\Pi_{\alpha, \beta}$ belongs to the class of double-CES functions widely used in multidimensional inequality and poverty analysis (see Atkinson 2003; Bosmans et al. 2015; Bourguignon 1999; Decancq and Ooghe 2010). It is called a double-CES because it uses a first CES function to aggregate at the individual level-across periods in our case or across goods in the multidimensional analysis - and a second CES function that aggregates at the social level. The sequence of aggregation associated with that functional form is important for distinguishing between anonymous versus non-anonymous pro-poor growth, as stressed in the multidimensional inequality and poverty literature. Indeed, if one first undertakes aggregation over different individuals for each period, and then undertakes aggregation over the different periods, then longitudinal poverty information is lost and only an anonymous evaluation of poverty can be performed. ${ }^{12}$

The shape of the iso-poverty curves of Fig. 2, showing a two-person two-period case with decreasing average poverty gap $\left(\Pi_{1}\left(g_{2}\right)<\Pi_{1}\left(g_{1}\right)\right)$, loss aversion $\left(\omega_{2}>\omega_{1}\right)$ and primacy of aversion to inequality over aversion to variability $(\alpha>\beta)$, is determined by the weights $\omega_{t}$ on the different periods and by the parameter $\beta$, expressing the degree of complementarity between periods, with $\beta=1$ corresponding to the case of perfect substitutes and $\beta \rightarrow \infty$ to the case of perfect complements. The parameter $\alpha$ determines the degree of inequality aversion. The case $\alpha=1$ corresponds to inequality neutrality with intertemporal ill-fare equal to the mean of least concave representations, and the case $\alpha \rightarrow \infty$ corresponds to the maximin rule with intertemporal ill-fare measured by the intertemporal poverty level of the individual in the worst position.

Our measure also reflects the property of correlation-increasing majorization introduced by Atkinson and Bourguignon (1982), which says that poverty should (weakly) increase after a correlation-increasing switch. A correlation-increasing switch can be seen on Fig. 1 when moving from profile $\bar{G}$ to profile $G$ : this does not change the distribution of incomes at each time period, but it does increase the temporal correlation of incomes. This property implies that the marginal social benefit of an income increment at period 1 (2) decreases with the income level at period 2 (1). This property also says that permuting the incomes of two poor individuals within a given period of time should (weakly) increase poverty if one of them then becomes more deprived than the other in both periods. This is the case when the cross-derivative of $\Pi_{\alpha, \beta}$ with respect $g_{i, 1}$ and $g_{i, 2}$ is positive, implying that $\alpha>\beta$.

Let

$$
c_{\alpha, \beta}:=\Pi_{\alpha, \beta}(\boldsymbol{G})-\Pi_{1, \beta}(\boldsymbol{G})
$$

be the cost of inequality of intertemporal poverty across individuals. This differs from:

$$
\frac{1}{n} \sum_{i=1}^{n} c_{\beta i}=\Pi_{1, \beta}(\boldsymbol{G})-\Pi_{1,1}(\boldsymbol{G}),
$$

\footnotetext{
12 See Dutta et al. (2003) and Decanq and Lugo (2012).
} 
which is the average cost of deprivation variability in the population. Substituting (12) into (11) and solving for $\Pi_{\alpha, \beta}(\boldsymbol{G})$, we find:

$$
\Pi_{\alpha, \beta}(\boldsymbol{G})=\frac{1}{n} \sum_{i=1}^{n} c_{\beta i}+c_{\alpha, \beta}+\Pi_{1,1}(\boldsymbol{G}) .
$$

Equation (13) expresses total intertemporal poverty as the sum of three components: the cost of poverty variability, the cost of inequality in intertemporal poverty and the average intertemporal poverty gap in the population.

Letting the benchmark deprivation matrix $\boldsymbol{G}_{1}$ correspond to the counterfactual income distribution $\boldsymbol{Y}_{1}$, we have $\Pi_{\alpha, \beta}\left(\boldsymbol{G}_{1}\right)=\Pi_{\alpha}\left(\boldsymbol{g}_{1}\right)$, with:

$$
\Pi_{\alpha}\left(g_{1}\right)=\left(\frac{1}{n} \sum_{i=1}^{n} g_{i, 1}^{\alpha}\right)^{\frac{1}{\alpha}}
$$

that is, initial cross-sectional poverty. The cost of inequality between individuals is the cost of inequality experienced in the initial period, that is, $c_{\alpha}\left(g_{1}\right)$.

The benchmark level of poverty can then be expressed as:

$$
\Pi_{\alpha}\left(g_{1}\right)=c_{\alpha}\left(g_{1}\right)+\Pi_{1}\left(g_{1}\right)
$$

which is the cost of inequality in the distribution of individual poverty gaps in the first period plus the average poverty gap in the first period.

\subsection{Intertemporal pro-poorness indices}

Using the poverty indices previously introduced, Eq. (3) can be expressed as:

$$
I P P_{\alpha, \beta}=\Pi_{\alpha}\left(g_{1}\right)-\Pi_{\alpha, \beta}(\boldsymbol{G}) .
$$

This index can be interpreted as the intertemporal poverty cost/gain, expressed in poverty gap units, of the observed growth process. It equals 0 when growth leaves everyone's deprivation unchanged. It is positive if intertemporal poverty is less than first-period poverty, and negative in the opposite case. If growth eliminates poverty in the subsequent periods, then $I P P_{\alpha, \beta}$ equals $\left(1-\omega_{1}\right) \Pi_{\alpha}\left(g_{1}\right)>0$. The upper bound for the IPP index is thus a simple discounted value of poverty experienced in the first period. $I P P_{\alpha, \beta}$ incorporates the cost of temporal variability and the benefits of a possible reduction of inequality in individual poverty, both due to the effects of mobility. IPP $P_{\alpha, \beta}$ obeys the usual social evaluation properties of population invariance, anonymity (in the identity of first-period incomes), scale invariance, continuity, and subgroup consistency. $I P P_{\alpha, \beta}$ is naturally increasing in the initial level of aggregate poverty and decreasing in the level of aggregate intertemporal poverty. The effects of a change in first-period gaps is ambiguous, as it affects both benchmark and intertemporal poverty. 


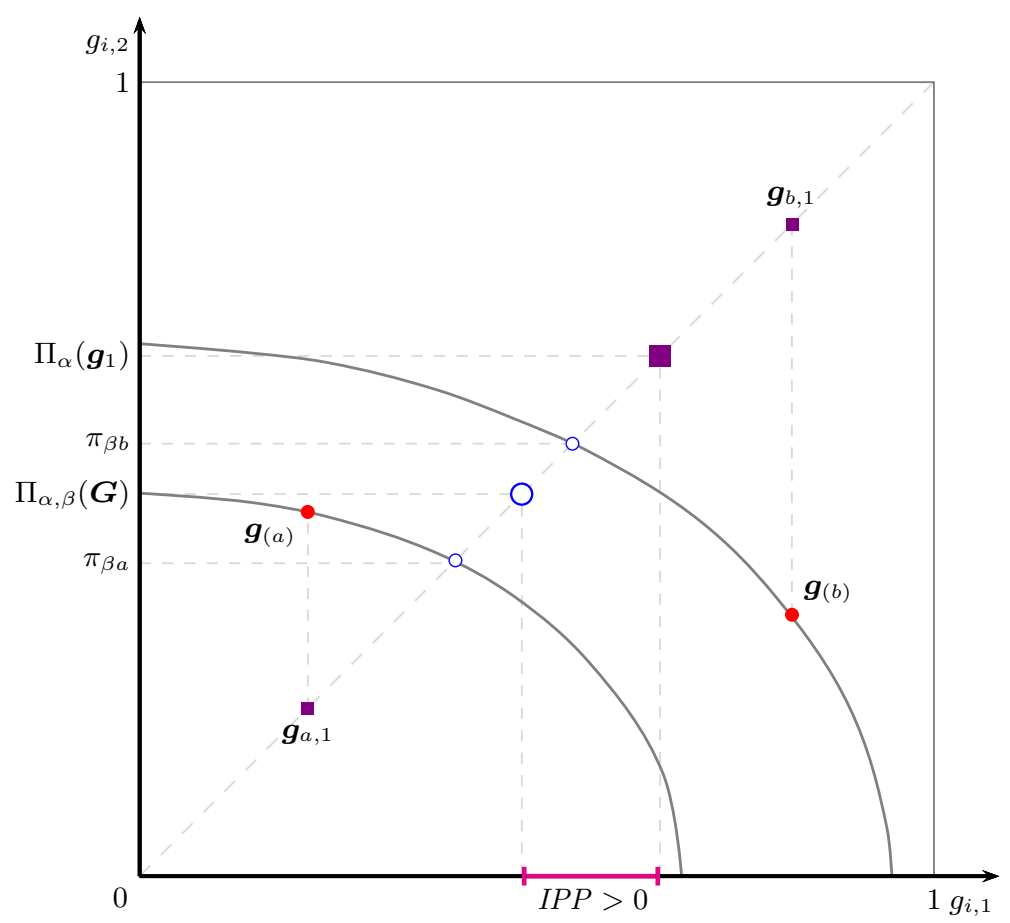

Fig. 2 The intertemporal pro-poorness of a two-period growth/mobility process. The iso-poverty contours correspond to the case of $\beta=2, \omega_{1}=\frac{1}{3}$, and $\omega_{2}=\frac{2}{3}$. For social aggregation, $\alpha$ is set equal to 3

It is worth underlining that the indices in (16) are normative in nature since they are derived from explicit social ill-fare functions and are measures of the change in intertemporal social ill-fare resulting from mobility. Such measures contrast with purely descriptive (or statistical) indices of mobility. Unlike purely descriptive indices, this paper's intertemporal pro-poor indices can help determine whether and by how much income changes were 'good' in reducing poverty and social ill-fare.

For the sake of illustration, consider again example (1) introduced earlier on page 1. As the average income gap is left unchanged during the growth process, the sign of $I P P_{\alpha, \beta}$ will depend on the value assigned to the parameter of aversion to poverty variability and to aversion to intertemporal poverty, whatever the choice of the weights $\omega_{t}$. In particular, for $\beta>\alpha$, variability aversion dominates aversion to poverty inequality and the other way round for $\beta<\alpha$. Let us consider the case of $\omega_{1}=\omega_{2}$. With greater weight to variability aversion-assume $\alpha=3$ and $\beta=4$ - the index is negative (e.g. $I P P_{3,4}=-0.016$ ), implying that the transformation is not pro-poor because of the cost of temporal variability. With $\alpha=3$ and $\beta=2$, the index is positive (e.g. $\left.I P P_{3,2}=0.029\right)$ and the transformation is pro-poor because of the dominating effect of poverty equalization.

Figure 2 illustrates the computation of $I P P_{\alpha, \beta}$ in a two-person two-period case with decreasing average poverty gap $\left(\Pi_{1}\left(g_{2}\right)<\Pi_{1}\left(g_{1}\right)\right)$, loss aversion $\left(\omega_{2}>\omega_{1}\right)$ 
and primacy of aversion to inequality over aversion to variability $(\alpha>\beta) .{ }^{13}$ The joint distribution of income gaps is shown by the two circular dots $\boldsymbol{g}_{(a)}$ and $\boldsymbol{g}_{(b)}$. One observes that the initially poorer individual (namely $b$ ) has benefited from a dramatic improvement in his situation, with the opposite happening to the initially less poor person ( $a$ ). The computation of $\pi_{\beta a}$ and $\pi_{\beta b}$ can be seen by projecting on one axis the points at which the iso-poverty curves for each poverty profile cross the diagonal of perfect immobility (the small circles). Aggregation across the population yields the EDE gap (the larger circle) $\Pi_{\alpha, \beta}(\boldsymbol{G})$. For the benchmark situation, we first generate the benchmark profiles (the small squares) by vertical projection of the observed profiles on the diagonal of perfect immobility. Aggregation across individuals leads to $\Pi_{\alpha}\left(g_{1}\right)$ (the large squares). The difference between $\Pi_{\alpha}\left(g_{1}\right)$ and $\Pi_{\alpha, \beta}(\boldsymbol{G})$ is here positive, indicating that growth has been pro-poor from an intertemporal perspective.

\section{Decompositions}

We now provide three decompositions of the $I P P_{\alpha, \beta}$ index. For expositional simplicity, we set $T=2$ for the first two decompositions. ${ }^{14}$

The first decomposition distinguishes the anonymous and the mobility components of growth. This is given by:

$$
I P P_{\alpha, \beta}=\underbrace{\Pi_{\alpha}\left(\boldsymbol{g}_{1}\right)-\Pi_{\alpha}\left(\boldsymbol{g}_{1}, \boldsymbol{g}_{2}\right)}_{A G}+\underbrace{\Pi_{\alpha}\left(\boldsymbol{g}_{1}, \boldsymbol{g}_{2}\right)-\Pi_{\alpha, \beta}\left(\boldsymbol{g}_{1}, \boldsymbol{g}_{2}\right)}_{M} .
$$

Recall that $\Pi_{\alpha}\left(g_{1}, g_{2}\right)$ is anonymous intertemporal poverty and does not account for the benefits or the costs of mobility. $A G$ therefore captures the poverty effect of anonymous growth, while $M$ captures the non-anonymous effects of mobility. $A G$ is positive if we observe both a decrease in the mean poverty gap and a contraction in the periodic distribution of poverty gaps. $M$ is positive when aversion towards inequality is stronger than aversion towards temporal variability $(\alpha>\beta)$, zero for $\beta=\alpha$, and otherwise negative. The sign of the two effects is not determined by the weights $\omega_{t}$. If $\beta=\alpha$, then $M=0 . \beta=1$ and $\alpha=1$ lead to neutrality to variability and inequality and to $M \geq 0$ and $M \leq 0$, respectively. Considering again the example given by (1), we have $A G=0$ and $M=0.029$ with $\alpha=3$ and $\beta=2$. Since the anonymous growth impact is nil, the growth effect on intertemporal poverty is entirely attributable to a (pro-poor) mobility effect.

Figure 3 illustrates this decomposition using the case shown in Fig. 2. The difference between the benchmark (the large square) and anonymous intertemporal poverty (the large pentagon) is positive, indicating that the $A G$ component is positive. As noted earlier, that result is due to a decrease in both the average poverty gap and in the poverty gap inequalities during the period. The effect of mobility is shown by the difference

\footnotetext{
13 The case $\alpha<\beta$ is illustrated on Fig. 9 in the Appendix. With the chosen values for the two individual profiles, for the periodic weights and $\beta$, it can be noticed that the sign of I P P does not depend on the value of $\alpha$. The magnitude of the index however increases with $\alpha$.

14 See the Appendix for a generalization to larger values of $T$.
} 


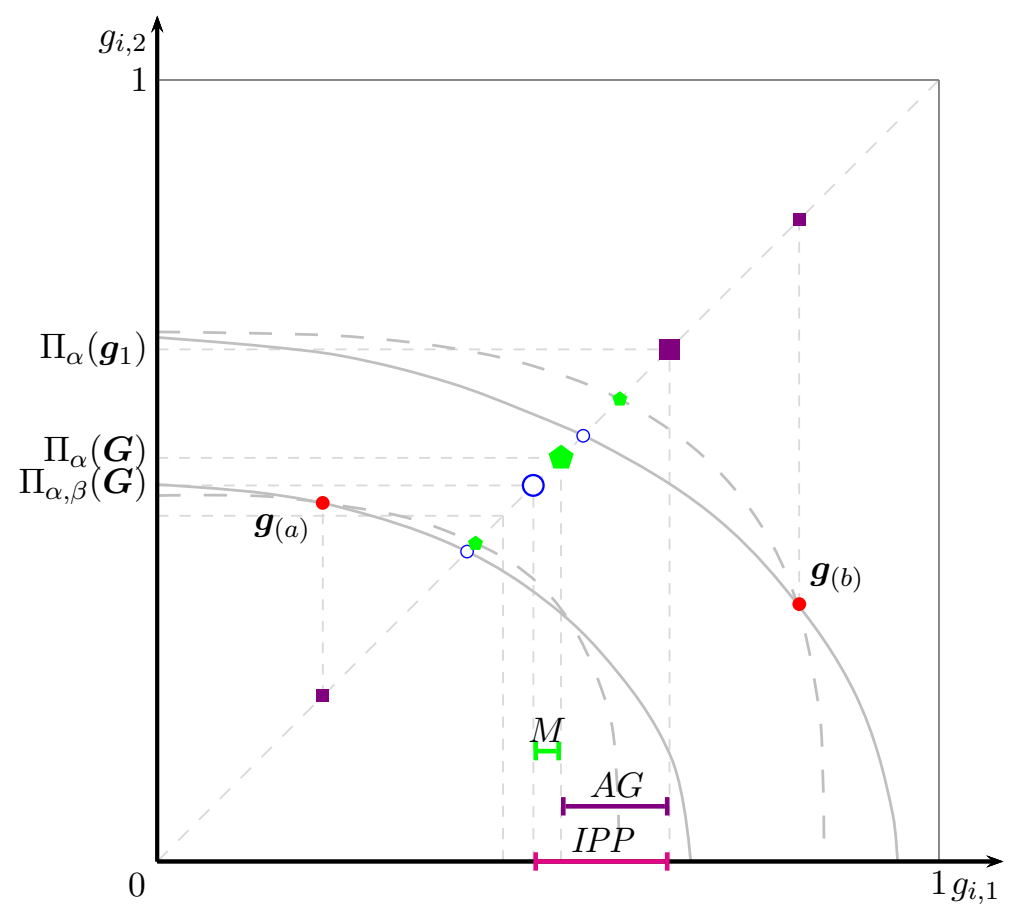

Fig. 3 Decomposing two-period intertemporal pro-poorness: growth and mobility. The iso-poverty contours correspond to the case of $\beta=2, \omega_{1}=\frac{1}{3}$ and $\omega_{2}=\frac{2}{3}$. For social aggregation, $\alpha$ is set equal to 3

between anonymous intertemporal poverty (the large pentagon) and the actual level of intertemporal poverty (the large circle), and is entirely determined by the values of $\alpha$ and $\beta$. Mobility exerts here a less important (but still positive) effect than the anonymous growth effect.

The second decomposition also considers the reranking effect of growth. It is obtained by making use of two counterfactual distributions that allow to isolate firstly the inequality component, secondly the reranking component, and lastly the pure growth component. The first counterfactual is denoted by $g_{1}^{I}$ and is obtained by scaling the second period's distribution of individual poverty gaps so that its mean is equal to the first period's mean poverty gap; $\boldsymbol{g}_{1}^{I}$ also orders poverty gaps by their ranks in the first period. The second counterfactual, denoted by $\boldsymbol{g}_{1}^{I R}$, is obtained by ordering the first period's gaps on the basis of the second period distribution's ranks. So, the only difference between $\boldsymbol{g}_{1}^{I}$ and $\boldsymbol{g}_{1}^{I R}$ is the order of individual gaps; $\boldsymbol{g}_{1}^{I R}$ and $\boldsymbol{g}_{2}$ only differ with respect to their average poverty gap. ${ }^{15}$

15 In the case of example (1) in the introduction, given the distribution of poverty gaps in the initial period and final period $\boldsymbol{g}_{1}=(0.43,0.14,0,0)$ and $\boldsymbol{g}_{2}=(0,0,0.43,0.14), \boldsymbol{g}_{1}^{I}$ is given by $\left(g_{3,2}, g_{4,2}, g_{1,2}, g_{2,2}\right) \times$ $\frac{P_{1}\left(g_{1}\right)}{P_{1}\left(g_{2}\right)}=(0.43,0.14,0,0) \times \frac{0.285}{0.285}$. 
The second decomposition is then given by ${ }^{16}$ :

$$
\begin{aligned}
I P P_{\alpha, \beta}= & \underbrace{\Pi_{\alpha}\left(\boldsymbol{g}_{1}\right)-\Pi_{\alpha, \beta}\left(\boldsymbol{g}_{1}, \boldsymbol{g}_{1}^{I}\right)}_{I}+\underbrace{\Pi_{\alpha, \beta}\left(\boldsymbol{g}_{1}, \boldsymbol{g}_{1}^{I}\right)-\Pi_{\alpha, \beta}\left(\boldsymbol{g}_{1}, \boldsymbol{g}_{1}^{I R}\right)}_{R} \\
& +\underbrace{\prod_{\alpha, \beta}\left(\boldsymbol{g}_{1}, \boldsymbol{g}_{1}^{I R}\right)-\Pi_{\alpha, \beta}\left(\boldsymbol{g}_{1}, \boldsymbol{g}_{2}\right)}_{P G} .
\end{aligned}
$$

The first component $I$ measures the intertemporal effects of inequality and variability in poverty ( $g_{1}$ and $g_{1}^{I}$ have the same mean and the same ranking of individuals). $I$ captures the effects of inequality across time and inequality across individuals when initial ranks are maintained. An increase in inequality will always result in $I$ being negative, no matter the combination of the values of the parameters. With $\alpha=\beta=1$, given neutrality to intertemporal variability and inequality in poverty, $I$ will be null.

The second component, $R$, captures the poverty effect of reranking ( $\boldsymbol{g}_{1}^{I R}$ and $\boldsymbol{g}_{1}^{I}$ have same mean and same cross-sectional inequality, but differ in the ranking of individuals). $R=0$ if there is no-reranking. When reranking occurs, the sign of $R$ will depend on the values of the parameters. For $\alpha<\beta, R<0$ because reranking generates time variability and the variability costs are deemed larger than the inequality benefits of reranking individuals; hence reranking harms intertemporal pro-poorness as it increases intertemporal poverty. Alternatively, $R>0$ for $\alpha>\beta$, since reranking helps equalize poverty over time and the equalization benefits are higher that the variability costs; hence reranking increases intertemporal pro-poorness. $\alpha=\beta=1$ implies $R=0$.

The third component $P G$ captures a pure growth effect on poverty. It will be positive (negative) if there is a reduction (increase) in intertemporal poverty due to pure growth. ${ }^{17}$

With the example given by (1), we have that $I=0$ since inequality is identical in both periods. Furthermore, $R=-0.016$ for $\alpha=3, \beta=4$, since there is a reshuffling of individuals in the distributions (the two initially poor individuals become the two richest) and the variability costs are higher than the benefits. Finally, $P G=0$ given that the average gap is unchanged.

The decomposition in Eq. (18) is sketched in Fig. 4 using the scenario of the earlier Fig. 3. In this situation, the inequality component $I$ contributes to pro-poorness as indicated by the difference between the benchmark (the large square) and the counterfactual profiles $\left(\mathbf{g}_{1}, \mathbf{g}_{1}^{I}\right)$ (the large diamond-shaped dots). The difference between the latter and the counterfactual scenario $\left(\mathbf{g}_{1}, \mathbf{g}_{1}^{I R}\right)$ (the large triangle) shows that reranking also supports pro-poorness, although to a lower extent than inequality. Finally, the impact of pure growth on pro-poorness is given by the difference between poverty in

\footnotetext{
16 See Ruiz-Castillo (2004) for a similar decomposition of the CDW (the Chakravarty et al. 1985) ethical index of mobility.

17 This decomposition is path-dependent. The value of the components would be different with different 'paths' for the decomposition. For instance, one might have wanted to capture first the growth effect, then the reranking effect and finally the inequality one (see, e.g. Fortin et al. 2011). An alternative procedure would be to apply a Shapley-Shorrocks decomposition, consisting of computing the Shapley-value of each effect across all possible paths of the decomposition (see Shorrocks 2013).
} 


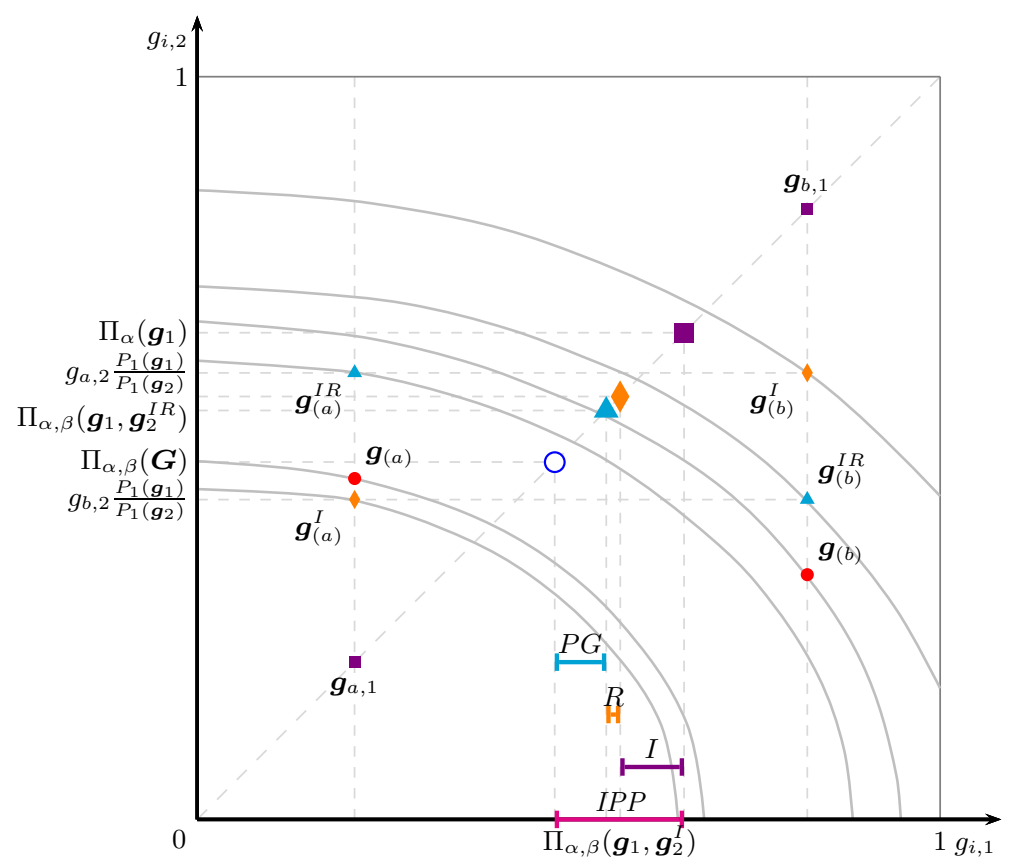

Fig. 4 Decomposing two-period intertemporal pro-poorness: inequality, reranking and growth. The isopoverty contours correspond to the case of $\beta=2, \omega_{1}=\frac{1}{3}$ and $\omega_{2}=\frac{2}{3}$. For social aggregation, $\alpha$ is set equal to 3

the counterfactual scenario $\left(\mathbf{g}_{1}, \mathbf{g}_{1}^{I R}\right)$ (the large triangle) and observed intertemporal poverty (the large circle); $P G$ is also supportive of pro-poorness.

Finally, it may be desirable to isolate the contribution of a specific subperiod, provided the available data makes it possible to perform a multi-period analysis $(T>2)$. Indeed, each subperiod may play a different role in the determination of intertemporal pro-poorness. To identify this role, we can make use of a sequence of comparisons of counterfactual distributions. Let $\mathbf{c}=\left(c_{1}, \ldots, c_{j} \ldots, c_{m}\right)$ be the vector of periods. The importance of period $c_{j}$ in generating $I P P_{\alpha, \beta}$ is measured by comparing the value of $I P P_{\alpha, \beta}$ when all subperiods are allowed to vary to the value of $I P P_{\alpha, \beta}$ when a specific subperiod $c_{j}$ is fixed. The contribution of a subperiod to inequality may depend on the order in which we eliminate the variations due to each of the subperiods. We account for this by implementing a Shapley-value decomposition (see Shorrocks 2013), which considers the marginal effect on $I P P_{\alpha, \beta}$ of accounting for each of the contributory factors - the subperiods in our case - in sequence and then assigns to each factor the average of its marginal contributions in all possible elimination sequences. This procedure yields an exact additive decomposition of $I P P_{\alpha, \beta}$ into the contributions of each subperiod. In practice, we assess all possible elimination sequences and take the contribution of each subperiod to be the average across all those. This is done, first, by generating the powerset of the $j$ subperiods considered. For each element in the powerset, we construct the index by allowing the subperiod included in the element to vary, and by eliminating the variation due to the other subperiods. Then, for each 
of the subperiods, we take every element of the powerset that does not include it, and compare pro-poorness in that set with the set that is otherwise identical but does include the subperiod. The importance of a subperiod is measured as the average of all such comparisons.

Let the generic poverty measure $\Pi_{\alpha, \beta}(\boldsymbol{G})$ be denoted by $\Pi_{\alpha, \beta}\left(\boldsymbol{g}_{1}, \ldots \boldsymbol{g}_{T}\right)$ and observe that benchmark poverty, $\Pi_{\alpha}\left(g_{1}\right)$, is given by $\Pi_{\alpha}\left(g_{1}, \ldots g_{1}\right)$. Assuming $T=3$ and denoting by $C_{\alpha, \beta}^{t}$ the contribution of growth to $I P P_{\alpha, \beta}$ of the subperiod from $t$ to $t+1$, the $I P P$ can be decomposed as:

$$
I P P_{\alpha, \beta}=C_{\alpha, \beta}^{1}+C_{\alpha, \beta}^{2},
$$

where a Shapley decomposition expresses $C_{\alpha, \beta}^{1}$ and $C_{\alpha, \beta}^{2}$ as follows:

$$
\begin{aligned}
C_{\alpha, \beta}^{1}= & \frac{1}{2}\left(\left(\Pi_{\alpha}\left(\boldsymbol{g}_{1}\right)-\Pi_{\alpha, \beta}\left(\boldsymbol{g}_{1}, f_{1,2}\left(\boldsymbol{g}_{1}\right), f_{1,2}\left(\boldsymbol{g}_{1}\right)\right)\right)\right. \\
& \left.+\left(\Pi_{\alpha, \beta}\left(\boldsymbol{g}_{1}, \boldsymbol{g}_{1}, f_{2,3}\left(\boldsymbol{g}_{1}\right)\right)-\Pi_{\alpha, \beta}\left(\boldsymbol{g}_{1}, f_{1,2}\left(\boldsymbol{g}_{1}\right), f_{2,3}\left(f_{1,2}\left(\boldsymbol{g}_{1}\right)\right)\right)\right)\right) \\
= & \frac{1}{2}\left(\left(\Pi_{\alpha}\left(\boldsymbol{g}_{1}\right)-\Pi_{\alpha, \beta}\left(\boldsymbol{g}_{1}, \boldsymbol{g}_{2}, \boldsymbol{g}_{2}\right)\right)\right. \\
& \left.+\left(\Pi_{\alpha, \beta}\left(\boldsymbol{g}_{1}, \boldsymbol{g}_{1}, f_{2,3}\left(\boldsymbol{g}_{1}\right)\right)-\Pi_{\alpha, \beta}\left(\boldsymbol{g}_{1}, \boldsymbol{g}_{2}, \boldsymbol{g}_{3}\right)\right)\right), \\
C_{\alpha, \beta}^{2}= & \frac{1}{2}\left(\left(\Pi_{\alpha}\left(\boldsymbol{g}_{1}\right)-\Pi_{\alpha, \beta}\left(\boldsymbol{g}_{1}, \boldsymbol{g}_{1}, f_{2,3}\left(\boldsymbol{g}_{1}\right)\right)\right)\right. \\
& +\left(\Pi_{\alpha, \beta}\left(\boldsymbol{g}_{1}, f_{1,2}\left(\boldsymbol{g}_{1}\right), f_{1,2}\left(\boldsymbol{g}_{1}\right)\right)-\Pi_{\alpha, \beta}\left(\boldsymbol{g}_{1}, f_{1,2}\left(\boldsymbol{g}_{1}\right), f_{2,3}\left(f_{1,2}\left(\boldsymbol{g}_{1}\right)\right)\right)\right) \\
= & \frac{1}{2}\left(\left(\Pi_{\alpha}\left(\boldsymbol{g}_{1}\right)-\Pi_{\alpha, \beta}\left(\boldsymbol{g}_{1}, \boldsymbol{g}_{1}, f_{2,3}\left(\boldsymbol{g}_{1}\right)\right)\right)\right. \\
& \left.+\left(\Pi_{\alpha, \beta}\left(\boldsymbol{g}_{1}, \boldsymbol{g}_{2}, \boldsymbol{g}_{2}\right)-\Pi_{\alpha, \beta}\left(\boldsymbol{g}_{1}, \boldsymbol{g}_{2}, \boldsymbol{g}_{3}\right)\right)\right),
\end{aligned}
$$

where $f_{t, t+1}\left(\boldsymbol{g}_{k}\right):=1-\boldsymbol{\delta}_{t, t+1}\left(1-\boldsymbol{g}_{k}\right)$ with $\boldsymbol{\delta}_{t, t+1}:=\left(\frac{\tilde{y}_{1, t}}{\tilde{y}_{1, t+1}}, \ldots \frac{\tilde{y}_{n, t}}{\tilde{y}_{n, t+1}}\right)$.

\section{Empirical illustration}

This section provides an empirical illustration of the tools developed above using the panel component of the Eurostat 'European Union Statistics on Income and Living Conditions' (EU-SILC). 


\subsection{Data}

The EU-SILC, which started in 2005, is a representative survey of the resident population within each European country, interviewed every year. The EU-SILC includes both a longitudinal and cross-sectional component. The EU-SILC is indeed a rotating panel survey in which the same households are interviewed in four consecutive years. The use of longitudinal weights makes the survey data representative of each country. Given the four-year constraint of the EU SILC rotating panel, we focus on the 2006-2009 period and, hence, use the 2006, 2007, 2008, and 2009 waves. Note that this time range covers the last European economic crisis and thus allows examining whether EU countries have performed differently in terms of pro-poorness during those challenging years.

The unit of observation used in the analysis is the individual. The measure of living standards is household disposable income, which includes all household members earnings, transfers, pensions, and capital incomes, net of taxes on wealth and incomes and of social insurance contributions. Incomes are expressed in Euros at PPP exchange rates and in constant 2005 prices and adjusted for differences in household size using the modified OECD equivalence scale. ${ }^{18}$ The countries considered are: Austria (AT), Belgium (BE), Bulgaria (BG), Cyprus (CY), Czech Republic (CZ), Estonia (EE), Spain (ES), Denmark (DK), Finland (FI), France (FR), Hungary (HU), Iceland (IS), Italy (IT), Latvia (LV), Lithuania (LT), Malta (MT), Netherlands (NL), Norway (NO), Poland (PL), Portugal (PT), Slovenia (SI), Sweden (SE), and United Kingdom (UK). We perform the illustration using country-specific poverty lines fixed to $60 \%$ of their 2006 median income.

\subsection{Results}

To evaluate the pro-poorness of the income transformation processes that took place between 2006, 2007, 2008, and 2009 for the 23 European countries listed above, we need to choose the weights $\omega_{t}$ as well as the parameters $\alpha$ and $\beta$ capturing aversions to inequality and to variability of poverty. For the sake of simplicity, we choose equal weights for all of the four periods. We fix $\alpha=2$, which is one of the most common values used in the poverty literature, and let $\beta$ be equal to 1 and 3 .

The numerical values of our estimates of intertemporal pro-poorness, for all combinations of the values of $\alpha$ and $\beta$ and all countries considered in this paper, are reported in Table 1 together with the annual growth rates of median incomes over the period. A graphical representation is available in Fig. 5, where countries are ordered according to the average value of the two $I P P_{\alpha, \beta}$ (namely $I P P_{2,1}, I P P_{2,3}$ ) such that $t=1$ is represented by $2006, t=2$ by $2007, t=3$ by $2008, t=4$ by $2009 .{ }^{19}$

A few general results stand out. First, although all countries were hit by the crisis, median individual incomes kept on rising up to 2009, in particular in the Eastern part of

\footnotetext{
18 The modified OECD scale makes the first adult count as a full consumption unit; each additional person aged 14 or more corresponds to 0.5 consumption unit, and each person aged 13 or less contributes to 0.3 consumption unit.

${ }^{19}$ For completeness, in Table 1 we also consider the case of $\beta=2$ and $\beta=\infty$
} 


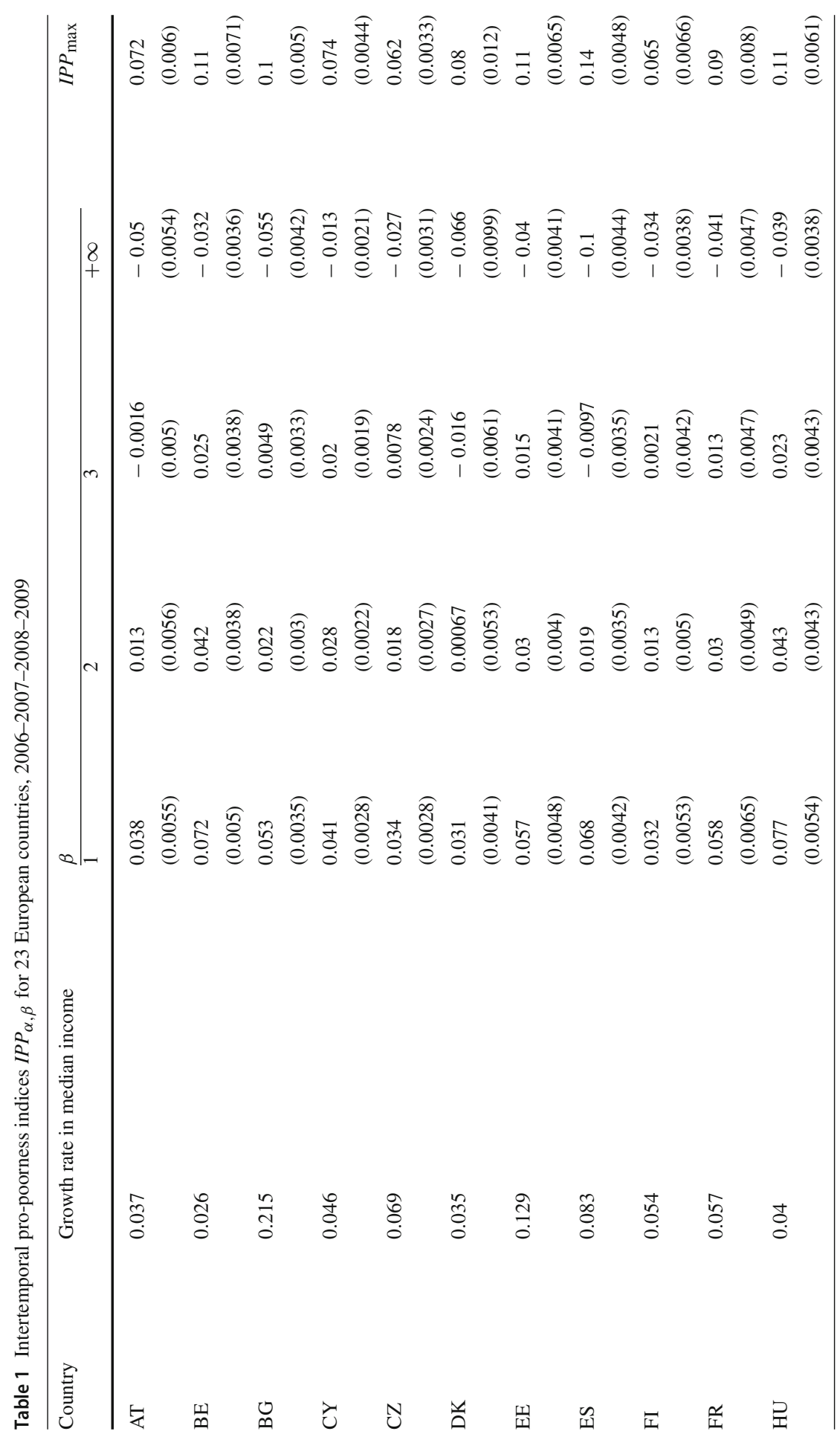




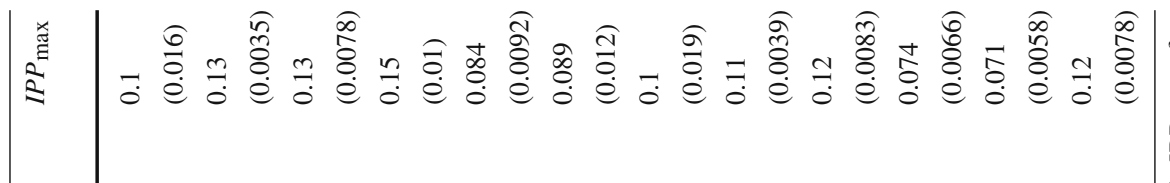

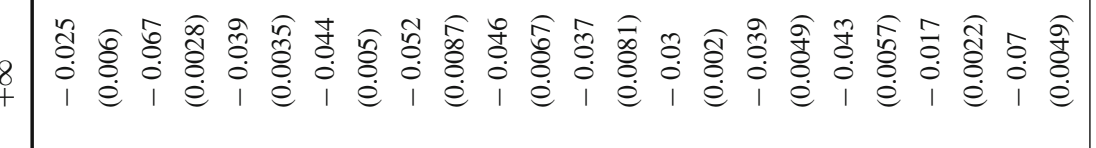

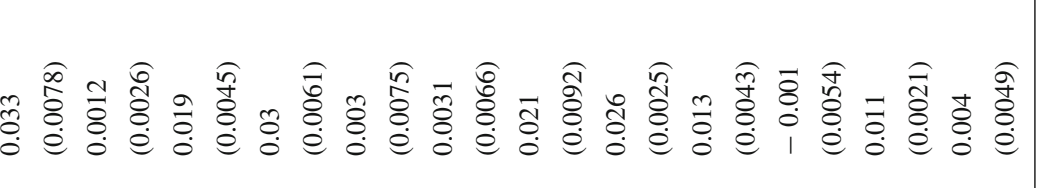

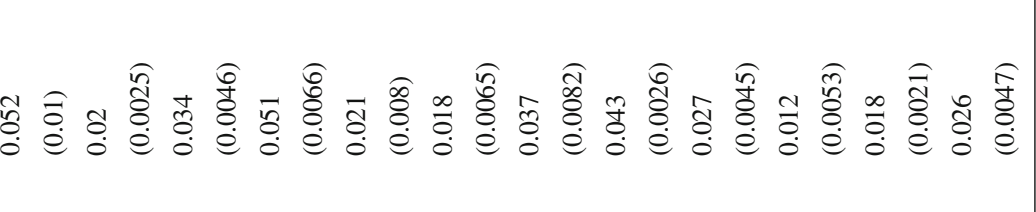

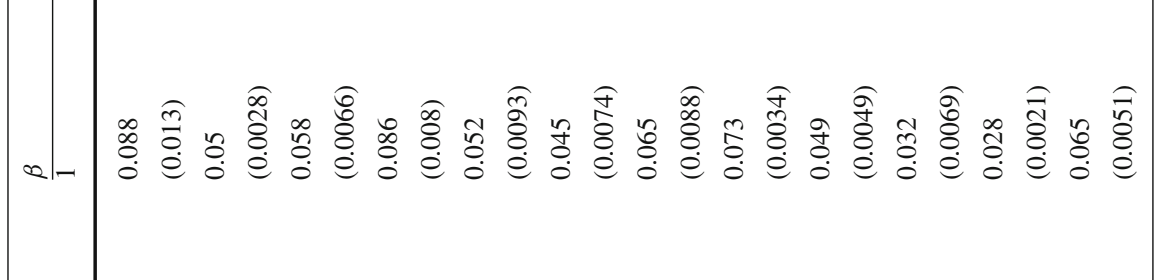

$$
\begin{aligned}
& \text {. } \\
& \text { 紊高 }
\end{aligned}
$$

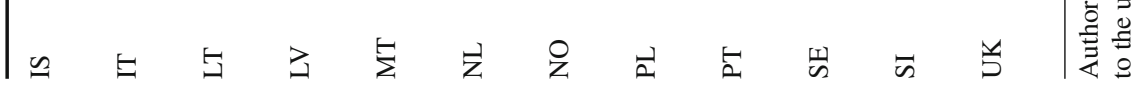




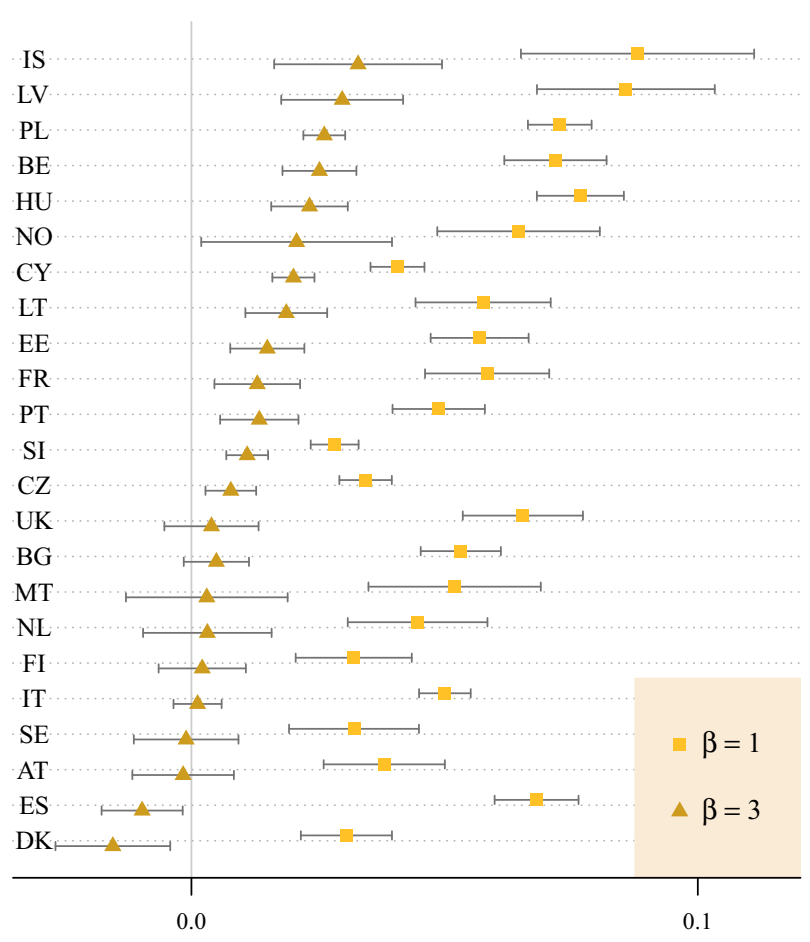

Fig. $5 I P P_{\alpha, \beta}, \alpha=2$, for different $\beta$ and for 23 European countries, 2006-2007-2008-2009, ordered by the average value of the $I P P_{\alpha, \beta}$. Authors' calculations based on EU-SILC. Whiskers show the $95 \%$ confidence interval (bootstrap with 200 replications)

Europe, the exception being the United Kingdom where median income fell between 2008 and 2009. These positive growth spells explain why the estimates reported in Table 1 and Fig. 5 generally show that growth was pro-poor in European countries between 2006 and 2009.

$I P P_{\alpha, \beta}$ is positive for all countries when $\alpha=2$ and $\beta=1$-that is when we are only concerned with inequality aversion-meaning that pro-poorness holds even with inequality aversion. When more importance is given to the costs of mobility than to its benefits ( $\alpha=2$ and $\beta=3$ ), the index becomes negative for Austria, Sweden, Denmark, and Spain, and statistically significant for the last two countries. Note that these four countries were not those with the lowest growth rates over the period, suggesting that income variability was higher in these countries.

As shown by the sub-period decomposition presented in Eq. (19) and in Fig. 6, the generally positive assessment of growth pro-poorness is mainly driven by the good economic performance initially observed in the period (See Table 2). If, in most cases, the post-2007 growth pattern had a positive effect on intertemporal growth propoorness in the absence of variability aversion, the contribution $C^{3}$ (2008-2009) is often not significantly different from zero. With variability aversion, the subperiods 2007-2008 and 2008-2009 generally had a significant and negative impact on growth pro-poorness, suggesting that the crisis introduced significant economic fluctuations. 
(a)

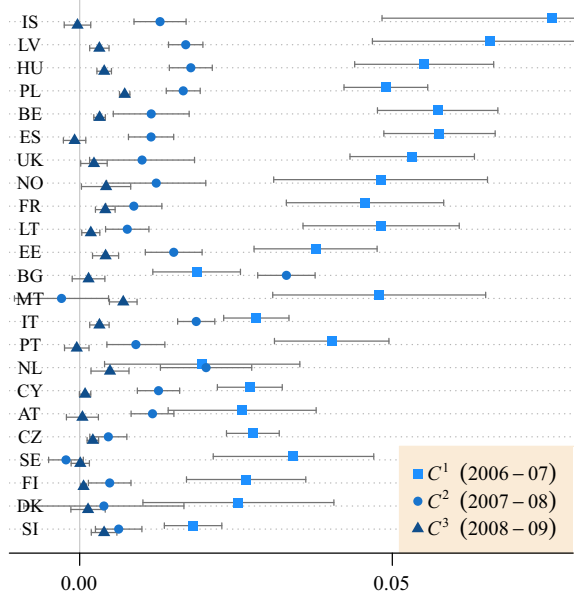

(b)

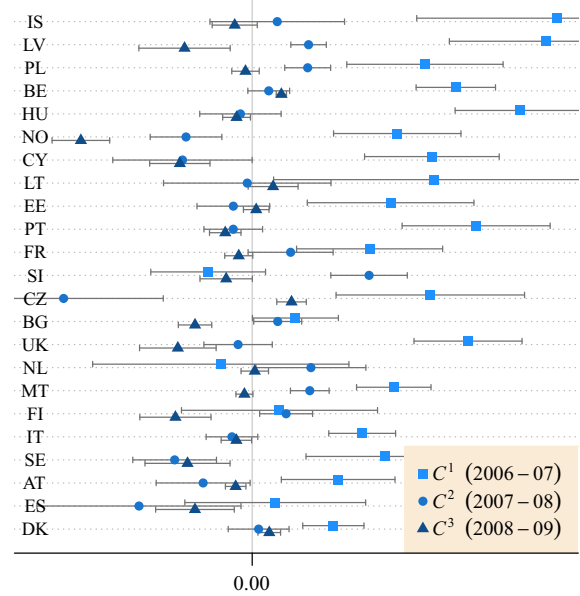

Fig. 6 IPP decomposition of the contribution of each period to the overall measure $\left(C_{\alpha, \beta}^{t}\right), 2006-2007-$ 2008-2009. a $\alpha=2, \beta=1$. b $\alpha=2, \beta=3$. Authors' calculations based on EU-SILC. Whiskers show the $95 \%$ confidence interval (bootstrap with 200 replications)

A second important feature emerging from Table 1 is the heterogeneity of European countries with respect to growth pro-poorness. Latin and Western European countries show contrasted results between 2006 and 2009. The experience in Eastern European countries seems to be more pro-poor on average than in other European countries, and later decompositions will show the crucial role of significant shifts in marginal distributions in that regard. In a single year (2009), Latvia and Lithuania lost as much as 18 and $15 \%$ of their respective GDP. The Romanian economy shrank by $8 \%$ in 2008-2010. While these economies eventually recovered, further south the crisis was more protracted. Contrasting with these results are those of otherwise more equal and richer countries like Denmark, Finland, and Sweden that rank poorly in terms of growth pro-poorness. This is somewhat surprising given the historical importance of safety nets in these countries. The Nordic countries are performing well in terms of initial levels of poverty and inequality, so that more favorable initial conditions may partly explain lower values for their IPP index; these countries have, however, also been affected by the surge in income inequality seen in many other developed countries (see for instance OECD (2015)) during the last decades.

Third, the country ranking depends on the normative importance given either to inequality or to variability, that is, it is dependent on values of $\beta$. Indeed, the sensitivity of $I P P_{\alpha, \beta}$ to the value of $\beta$ provides valuable summary information on variability in deprivation. Changes in the estimated value of the pro-poorness index after an increment in $\beta$ vary considerably from country to country. Differences between $I P P_{2,1}$ and $I P P_{2,3}$ are more than twice lower for Cyprus, the Czech Republic, and Slovenia than for Latvia, United Kingdom, and Spain. While poverty gap fluctuations appear relatively limited within these first three countries, the evidence points to much larger variability at the bottom of the income distribution in the three other countries (Table 1). 
Table 2 Subperiod contributions to intertemporal growth pro-poorness for 23 European countries, 20062007-2008-2009. $C^{1}:$ 2006-2007; $C^{2}: 2007-2008 ; C^{3}: 2008-2009$

\begin{tabular}{|c|c|c|c|c|c|c|}
\hline \multirow[t]{2}{*}{ Country } & \multicolumn{3}{|c|}{$(\alpha=2, \beta=1)$} & \multicolumn{3}{|c|}{$(\alpha=2, \beta=3)$} \\
\hline & $\bar{C}^{1}$ & $C^{2}$ & $C^{3}$ & $\bar{C}^{1}$ & $C^{2}$ & $C^{3}$ \\
\hline \multirow[t]{2}{*}{ AT } & 0.026 & 0.012 & 0.00044 & 0.0029 & 0.0036 & -0.0081 \\
\hline & $(0.006)$ & $(0.0017)$ & $(0.0013)$ & $(0.0053)$ & $(0.0014)$ & $(0.0019)$ \\
\hline \multirow[t]{2}{*}{$\mathrm{BE}$} & 0.057 & 0.011 & 0.0032 & 0.028 & -0.0012 & -0.0016 \\
\hline & $(0.0049)$ & $(0.0031)$ & $(0.00047)$ & $(0.0035)$ & $(0.0022)$ & $(0.00074)$ \\
\hline \multirow[t]{2}{*}{ BG } & 0.019 & 0.033 & 0.0014 & -0.0046 & 0.012 & -0.0027 \\
\hline & $(0.0036)$ & $(0.0023)$ & $(0.0013)$ & $(0.0031)$ & $(0.0021)$ & $(0.0014)$ \\
\hline \multirow[t]{2}{*}{$\mathrm{CY}$} & 0.027 & 0.013 & 0.00087 & 0.015 & 0.0061 & -0.00082 \\
\hline & $(0.0026)$ & $(0.0017)$ & $(0.00046)$ & $(0.002)$ & $(0.001)$ & $(0.00046)$ \\
\hline \multirow[t]{2}{*}{$\mathrm{CZ}$} & 0.028 & 0.0046 & 0.0021 & 0.012 & -0.0021 & -0.0017 \\
\hline & $(0.0022)$ & $(0.0015)$ & $(0.00047)$ & $(0.0018)$ & $(0.0014)$ & $(0.00082)$ \\
\hline \multirow[t]{2}{*}{ DK } & 0.025 & 0.0039 & 0.0013 & 0.0024 & -0.012 & -0.006 \\
\hline & $(0.0078)$ & $(0.0065)$ & $(0.0014)$ & $(0.0049)$ & $(0.0055)$ & $(0.0021)$ \\
\hline \multirow[t]{2}{*}{$\mathrm{EE}$} & 0.038 & 0.015 & 0.0041 & 0.012 & 0.004 & -0.0014 \\
\hline & $(0.005)$ & $(0.0023)$ & $(0.0011)$ & $(0.0039)$ & $(0.0023)$ & $(0.00075)$ \\
\hline \multirow[t]{2}{*}{ ES } & 0.058 & 0.011 & -0.00081 & 0.015 & -0.007 & -0.018 \\
\hline & $(0.0045)$ & $(0.0018)$ & $(0.00091)$ & $(0.0034)$ & $(0.0019)$ & $(0.0015)$ \\
\hline \multirow[t]{2}{*}{ FI } & 0.027 & 0.0048 & 0.00062 & 0.009 & -0.0052 & -0.0017 \\
\hline & $(0.0049)$ & $(0.0017)$ & $(0.00024)$ & $(0.0031)$ & $(0.0025)$ & $(0.00055)$ \\
\hline \multirow[t]{2}{*}{ FR } & 0.046 & 0.0087 & 0.0041 & 0.015 & -0.002 & 0.00042 \\
\hline & $(0.0064)$ & $(0.0023)$ & $(0.0008)$ & $(0.0045)$ & $(0.002)$ & $(0.00069)$ \\
\hline \multirow[t]{2}{*}{$\mathrm{HU}$} & 0.055 & 0.018 & 0.0039 & 0.018 & 0.0058 & -0.00071 \\
\hline & $(0.0057)$ & $(0.0018)$ & $(0.00059)$ & $(0.0042)$ & $(0.0012)$ & $(0.00074)$ \\
\hline
\end{tabular}

Previous studies concerned with the distributional implications of the earlier phases of the great recession found similar results in terms of poverty dynamics: in the majority of countries, poverty did not increase and in some cases decreased (see, among others, Jenkins et al. 2012). However, these studies were based on measures of unitemporal and cross-sectional poverty. In particular, introducing concerns for variability over the potentially negative impact of the crisis on intertemporal poverty can serve to underline the important role played by economic insecurity in the decision making process of individuals and households (see, among others, Rohde et al. 2017; Western et al. 2012).

We proceed by performing the decompositions introduced above, each of them emphasizing a distinct aspect of growth pro-poorness. For expositional simplicity, we focus on two cases: (i) $\alpha=2, \beta=1$; and (ii) $\alpha=2, \beta=3$. The estimates of the elements of the first anonymous/non-anonymous decomposition are reported in Table 3, where countries are ranked alphabetically. A more synthetic representation of the results is shown in Fig. 7, where countries are ordered by decreasing values of $I P P_{\alpha, \beta}$. 
Table 2 continued

\begin{tabular}{|c|c|c|c|c|c|c|}
\hline \multirow[t]{2}{*}{ Country } & \multicolumn{3}{|c|}{$(\alpha=2, \beta=1)$} & \multicolumn{3}{|c|}{$(\alpha=2, \beta=3)$} \\
\hline & $\bar{C}^{1}$ & $C^{2}$ & $C^{3}$ & $\bar{C}^{1}$ & $C^{2}$ & $C^{3}$ \\
\hline \multirow[t]{2}{*}{ IS } & 0.076 & 0.013 & -0.00035 & 0.032 & 0.0026 & -0.0018 \\
\hline & $(0.014)$ & $(0.0021)$ & $(0.0011)$ & $(0.0076)$ & $(0.0036)$ & $(0.0012)$ \\
\hline \multirow[t]{2}{*}{ IT } & 0.028 & 0.019 & 0.0032 & 0.0045 & 0.0027 & -0.006 \\
\hline & $(0.0027)$ & $(0.0015)$ & $(0.00079)$ & $(0.0023)$ & $(0.0013)$ & $(0.0009)$ \\
\hline \multirow[t]{2}{*}{ LT } & 0.048 & 0.0076 & 0.0018 & 0.024 & -0.002 & -0.0028 \\
\hline & $(0.0064)$ & $(0.0018)$ & $(0.00074)$ & $(0.004)$ & $(0.0016)$ & $(0.00085)$ \\
\hline \multirow[t]{2}{*}{ LV } & 0.066 & 0.017 & 0.0032 & 0.031 & 0.0059 & -0.0071 \\
\hline & $(0.0096)$ & $(0.0014)$ & $(0.00079)$ & $(0.0052)$ & $(0.00095)$ & $(0.0025)$ \\
\hline \multirow[t]{2}{*}{ MT } & 0.048 & -0.0029 & 0.007 & 0.019 & -0.02 & 0.0041 \\
\hline & $(0.0087)$ & $(0.0038)$ & $(0.0011)$ & $(0.0051)$ & $(0.0054)$ & $(0.00079)$ \\
\hline \multirow[t]{2}{*}{ NL } & 0.02 & 0.02 & 0.0049 & -0.0033 & 0.0062 & 0.00027 \\
\hline & $(0.008)$ & $(0.0037)$ & $(0.0015)$ & $(0.0069)$ & $(0.003)$ & $(0.00074)$ \\
\hline \multirow[t]{2}{*}{$\mathrm{NO}$} & 0.048 & 0.012 & 0.0042 & 0.019 & -0.00052 & 0.0022 \\
\hline & $(0.0087)$ & $(0.004)$ & $(0.002)$ & $(0.0086)$ & $(0.0045)$ & $(0.0013)$ \\
\hline \multirow[t]{2}{*}{ PL } & 0.049 & 0.017 & 0.0072 & 0.021 & 0.0017 & 0.0031 \\
\hline & $(0.0034)$ & $(0.0014)$ & $(0.00042)$ & $(0.0021)$ & $(0.0011)$ & $(0.00027)$ \\
\hline \multirow[t]{2}{*}{ PT } & 0.04 & 0.009 & -0.00046 & 0.023 & -0.0015 & -0.0078 \\
\hline & $(0.0047)$ & $(0.0024)$ & $(0.001)$ & $(0.0029)$ & $(0.0018)$ & $(0.0021)$ \\
\hline \multirow[t]{2}{*}{ SE } & 0.034 & -0.0022 & 0.000098 & 0.014 & -0.0082 & -0.0068 \\
\hline & $(0.0065)$ & $(0.0014)$ & $(0.00074)$ & $(0.0042)$ & $(0.0022)$ & $(0.0023)$ \\
\hline \multirow[t]{2}{*}{ SI } & 0.018 & 0.0062 & 0.0039 & 0.0085 & 0.00068 & 0.0018 \\
\hline & $(0.0023)$ & $(0.0019)$ & $(0.001)$ & $(0.0016)$ & $(0.0016)$ & $(0.00061)$ \\
\hline \multirow[t]{2}{*}{ UK } & 0.053 & 0.01 & 0.0023 & 0.019 & -0.0073 & -0.0076 \\
\hline & $(0.0051)$ & $(0.0043)$ & $(0.0011)$ & $(0.0036)$ & $(0.0037)$ & $(0.0016)$ \\
\hline
\end{tabular}

Authors' calculations based on EU-SILC. Bootstrapped standard errors in parentheses (200 replications)

Table 3 shows the discrepancy between anonymous and non-anonymous evaluations of growth pro-poorness. With the notable exception of Denmark, the anonymous evaluation indicates that growth was significantly pro-poor between 2006 and 2009 for our sample of European countries. ${ }^{20}$ For low values of the variability aversion parameter, this picture does not change, but since variability was significant in our sample of European countries, the significance of pro-poorness decreases with a nonanonymous evaluation. The negative impact of variability is sometimes strong enough to reverse the sign of the measure of growth pro-poorness. For instance, $I P P_{2,3}$ is negative for four out of the 23 countries. For these countries, the cost of variability exceeds the intertemporal inequality reduction and growth benefits of the income transforma-

20 These results are generally robust to moderate changes in the value $\alpha$, although the use of larger values for the inequality aversion parameter results in some growth spells being regarded as anti-poor. This is for instance the case for Denmark ( $\alpha \geq 2.1$ ), Bulgaria ( $\alpha \geq 4.4$ ), Sweden ( $\alpha \geq 4.7)$, the Czech Republic ( $\alpha \geq 5.4$ ), Finland ( $\alpha \geq 6.4)$, Spain $(\alpha \geq 9.3)$, and Italy $(\alpha \geq 21.8)$. 
Table 3 Decomposition into anonymous $(A G)$ and non-anonymous $(M)$ pro-poorness of growth for 23 European countries, 2006-2007-2008-2009

\begin{tabular}{|c|c|c|c|c|c|}
\hline \multirow[t]{2}{*}{ Country } & \multicolumn{3}{|c|}{$(\alpha=2, \beta=1)$} & \multicolumn{2}{|c|}{$(\alpha=2, \beta=3)$} \\
\hline & $\overline{I P P}$ & $\mathrm{AG}$ & $\mathrm{M}$ & $\overline{I P P}$ & $\mathrm{M}$ \\
\hline \multirow[t]{2}{*}{ AT } & 0.038 & 0.013 & 0.025 & -0.0016 & -0.015 \\
\hline & $(0.0057)$ & $(0.0053)$ & $(0.0017)$ & $(0.0052)$ & $(0.0007)$ \\
\hline \multirow[t]{2}{*}{$\mathrm{BE}$} & 0.072 & 0.042 & 0.03 & 0.025 & -0.017 \\
\hline & $(0.0046)$ & $(0.0041)$ & $(0.0016)$ & $(0.0038)$ & $(0.0007)$ \\
\hline \multirow[t]{2}{*}{ BG } & 0.053 & 0.022 & 0.031 & 0.0049 & -0.017 \\
\hline & $(0.0035)$ & $(0.0031)$ & $(0.0011)$ & $(0.0031)$ & $(0.0006)$ \\
\hline \multirow[t]{2}{*}{ CY } & 0.041 & 0.028 & 0.012 & 0.02 & -0.0081 \\
\hline & $(0.0026)$ & $(0.0021)$ & $(0.0009)$ & $(0.0021)$ & $(0.0004)$ \\
\hline \multirow[t]{2}{*}{$\mathrm{CZ}$} & 0.034 & 0.018 & 0.017 & 0.0078 & -0.0099 \\
\hline & $(0.0029)$ & $(0.0025)$ & $(0.0009)$ & $(0.0023)$ & $(0.0004)$ \\
\hline \multirow[t]{2}{*}{ DK } & 0.031 & 0.0006 & 0.03 & -0.016 & -0.016 \\
\hline & $(0.0043)$ & $(0.005)$ & $(0.0021)$ & $(0.0062)$ & $(0.0013)$ \\
\hline \multirow[t]{2}{*}{$\mathrm{EE}$} & 0.057 & 0.03 & 0.027 & 0.015 & -0.015 \\
\hline & $(0.0047)$ & $(0.004)$ & $(0.0015)$ & $(0.004)$ & $(0.0006)$ \\
\hline \multirow[t]{2}{*}{ ES } & 0.068 & 0.019 & 0.049 & -0.0097 & -0.028 \\
\hline & $(0.0045)$ & $(0.0036)$ & $(0.0015)$ & $(0.0036)$ & $(0.0007)$ \\
\hline \multirow[t]{2}{*}{ FI } & 0.032 & 0.013 & 0.019 & 0.0021 & -0.011 \\
\hline & $(0.0054)$ & $(0.0044)$ & $(0.0013)$ & $(0.0046)$ & $(0.0007)$ \\
\hline \multirow[t]{2}{*}{ FR } & 0.058 & 0.03 & 0.029 & 0.013 & -0.017 \\
\hline & $(0.0064)$ & $(0.0049)$ & $(0.0016)$ & $(0.0045)$ & (0.0009) \\
\hline \multirow[t]{2}{*}{$\mathrm{HU}$} & 0.077 & 0.043 & 0.034 & 0.023 & -0.019 \\
\hline & $(0.005)$ & $(0.0045)$ & $(0.0014)$ & $(0.0041)$ & $(0.0008)$ \\
\hline \multirow[t]{2}{*}{ IS } & 0.088 & 0.052 & 0.036 & 0.033 & -0.019 \\
\hline & $(0.013)$ & $(0.01)$ & $(0.0037)$ & $(0.0084)$ & (0.0019) \\
\hline \multirow[t]{2}{*}{ IT } & 0.05 & 0.02 & 0.03 & 0.0012 & -0.018 \\
\hline & $(0.0027)$ & $(0.0027)$ & $(0.0008)$ & $(0.0026)$ & $(0.0004)$ \\
\hline \multirow[t]{2}{*}{ LT } & 0.058 & 0.034 & 0.024 & 0.019 & -0.015 \\
\hline & $(0.0066)$ & $(0.0056)$ & $(0.0021)$ & $(0.004)$ & $(0.0011)$ \\
\hline \multirow[t]{2}{*}{ LV } & 0.086 & 0.051 & 0.035 & 0.03 & -0.021 \\
\hline & $(0.0085)$ & $(0.0074)$ & $(0.0026)$ & $(0.0056)$ & $(0.0016)$ \\
\hline \multirow[t]{2}{*}{ MT } & 0.052 & 0.021 & 0.031 & 0.003 & -0.018 \\
\hline & $(0.0089)$ & $(0.008)$ & $(0.0024)$ & $(0.0082)$ & $(0.0013)$ \\
\hline \multirow[t]{2}{*}{ NL } & 0.045 & 0.018 & 0.027 & 0.0031 & -0.015 \\
\hline & $(0.0077)$ & $(0.0077)$ & (0.0019) & $(0.0067)$ & (0.0009) \\
\hline \multirow[t]{2}{*}{ NO } & 0.065 & 0.037 & 0.028 & 0.021 & -0.016 \\
\hline & $(0.0087)$ & $(0.0088)$ & $(0.0027)$ & (0.009) & $(0.0012)$ \\
\hline \multirow[t]{2}{*}{ PL } & 0.073 & 0.043 & 0.03 & 0.026 & -0.017 \\
\hline & $(0.0033)$ & $(0.0026)$ & $(0.0009)$ & $(0.0022)$ & $(0.0005)$ \\
\hline
\end{tabular}


Table 3 continued

\begin{tabular}{lllllll}
\hline Country & \multicolumn{2}{l}{$(\alpha=2, \beta=1)$} & & & \multicolumn{2}{l}{$(\alpha=2, \beta=3)$} \\
\cline { 2 - 3 } & IPP & AG & M & & M \\
\hline PT & 0.049 & 0.027 & 0.022 & & 0.013 & -0.014 \\
& $(0.0054)$ & $(0.004)$ & $(0.0017)$ & & $(0.0041)$ & $(0.0009)$ \\
SE & 0.032 & 0.012 & 0.02 & & -0.001 & -0.013 \\
& $(0.0062)$ & $(0.0055)$ & $(0.0023)$ & & $(0.0048)$ & $(0.0011)$ \\
SI & 0.028 & 0.018 & 0.011 & & 0.011 & -0.0067 \\
& $(0.0024)$ & $(0.002)$ & $(0.0007)$ & & $(0.0022)$ & $(0.0003)$ \\
UK & 0.065 & 0.026 & 0.039 & & 0.004 & -0.022 \\
& $(0.0059)$ & $(0.005)$ & $(0.0017)$ & $(0.0048)$ & $(0.0009)$ \\
\hline
\end{tabular}

Authors' calculations based on EU-SILC. Bootstrapped standard errors in parentheses (200 replications). The value of $A G$ is not reported for $I P P_{2,3}$ since that component does not depend on $\beta$

(a)

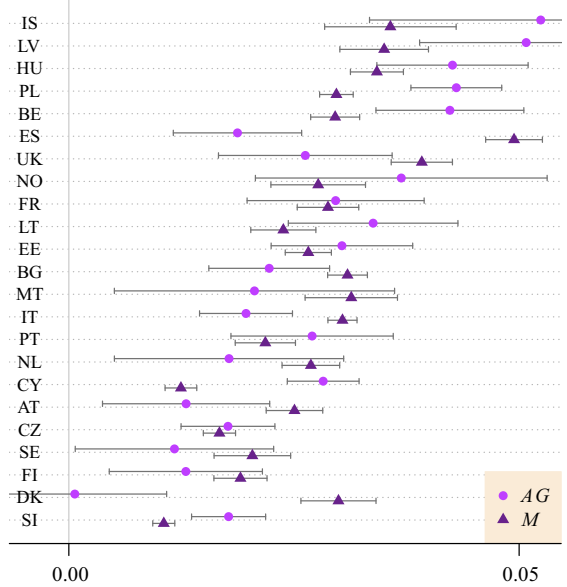

(b)

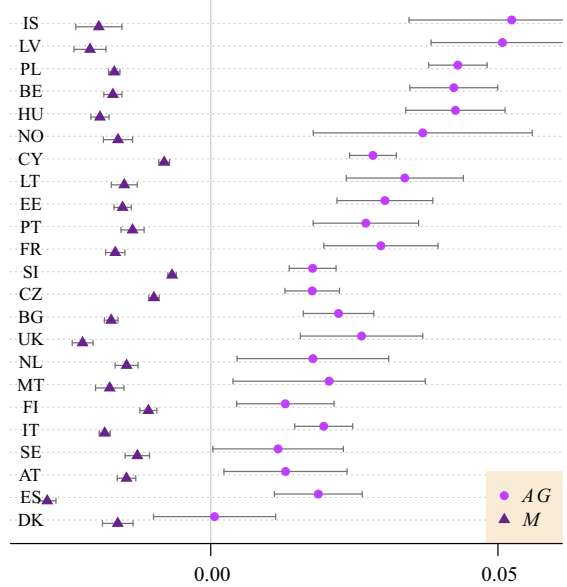

Fig. $7 I P P$ decomposition into anonymous $(A G)$ and mobility $(M)$ components for 23 European countries, 2006-2007-2008-2009. a $\alpha=2, \beta=1$. b $\alpha=2, \beta=3$. Authors' calculations based on EU-SILC. Whiskers show the $95 \%$ confidence interval (bootstrap with 200 replications)

tion. The results of the decomposition further highlight the contrast between Nordic countries - with lower values of $A G$ - and Eastern European countries-with larger values of $A G$. Moreover, the varying sensitivity of $I P P_{\alpha, \beta}$ to $\beta$ is explained by the magnitude of the mobility component, with Latvia, Great Britain, and Spain showing the largest absolute values for $M$ and with the values for Cyprus, Slovenia, and the Czech Republic being closer to zero.

Finally, the inequality reduction effect of mobility can also be sizable. Figure 7 (left panel) shows that the benefits of the intertemporal equalization effects often affect propoorness more strongly than the anonymous changes. With $\alpha=2$ and $\beta=1$, it is clear that both anonymous growth and the mobility benefits of intertemporal equalization affect intertemporal pro-poorness, but the shares of $A G$ and $M$ in total $I P P_{2,1}$ 
vary considerably across countries. Denmark (DK) is perhaps the most extreme case since intertemporal pro-poorness is explained entirely by the intertemporal inequality reduction benefits. This describes a situation in which anonymous cross-sectional poverty remains stable over the period but in which the individual deprivation profiles of the poor vary across time.

The results of this decomposition give support to our initial hypothesis that the distributional dynamics of the European countries, considered in that period, was made up by different components that acted differently on the overall growth process. The large number of papers and reports on the poverty impact of the crisis has suggested that the dramatic reduction of GDP was not immediately translated into a worsening of poverty or inequality. Some of the literature has also hinted that fiscal adjustments may have led to adverse distributional and poverty outcomes. Those outcomes are naturally individual-specific (see, among others, Matsaganis and Leventi 2014; Bargain et al. 2017); an individual-focussed approach such as the one of this paper shows how individual income mobility and income variability can affect our understanding of the joint growth/policy process, even over a relatively short time horizon.

The results of the second decomposition (inequality change $I$, reranking $R$, and pure growth $P G$ ) are reported in Table 4 and Fig. 8 . Consistent with the positive growth rates reported in Table 1 , the pure growth effect is everywhere positive. The inequality component is significantly negative: rising inequalities in Europe have also been associated with anti-poor effects during the crisis. Finally, the effects of reranking are modest compared with those of inequality changes and pure growth.

The decomposition shows again a marked difference between Nordic and Southern European countries on the one hand and Eastern European countries on the other hand. The magnitude of $I$ and $P G$ is about half as low for the former group as it is for the latter group. This is the result of both larger growth rates over the period and greater inequalities in the benefits of growth in Eastern European countries between 2006 and 2009.

To sum up briefly, the empirical results display considerable variability in the size and determinants of intertemporal pro-poorness across European countries between 2006 and 2009. The evidence mirrors the diversity of poverty experiences both across and within countries. The convergence process within Europe during the first decade of the twenty-first century has helped Eastern European countries achieve growth pro-poorness, though inequality changes have had a detrimental effect. Judgments on intertemporal pro-poorness among Western European and Mediterranean countries depend on the importance given to inequality and variability aversion, especially for countries such as Spain and the United Kingdom where the cost of variability among the poor is found to be particularly significant.

The distributional impacts of the crisis have been the topic of a considerable number of contributions, both from national international perspectives (see for instance Bargain et al. 2017; Callan et al. 2011; Immervoll et al. 2011; Jenkins et al. 2012; Matsaganis and Leventi 2014). They have analyzed the distributional impact of the crisis using a cross-sectional lens and have often disentangled pure growth effects from tax-benefit-change effects. This paper's approach uses a non-anonymous and intertemporal lens and thus enables seeing how distributional dynamics come into play during a growth/policy-change process. In agreement with earlier work, the paper's results indicate that the earlier phase of the crisis did not lead to significant intertemporal 
Table 4 Decomposition into inequality change $(I)$, reranking $(R)$, and pure growth effects $(P G)$ for 23 European countries, 2006-2007-2008-2009

\begin{tabular}{|c|c|c|c|c|c|c|}
\hline \multirow[t]{2}{*}{ Country } & \multicolumn{3}{|c|}{$(\alpha=2, \beta=1)$} & \multicolumn{3}{|c|}{$(\alpha=2, \beta=3)$} \\
\hline & $\bar{I}$ & $R$ & $P G$ & $\bar{I}$ & $R$ & $P G$ \\
\hline \multirow{2}{*}{ AT } & -0.013 & 0.031 & 0.02 & -0.016 & -0.018 & 0.033 \\
\hline & $(0.0016)$ & $(0.0015)$ & $(0.0025)$ & $(0.0022)$ & $(0.00089)$ & $(0.0044)$ \\
\hline \multirow[t]{2}{*}{$\mathrm{BE}$} & -0.044 & 0.048 & 0.068 & -0.058 & -0.026 & 0.11 \\
\hline & $(0.0014)$ & $(0.001)$ & $(0.0018)$ & $(0.0021)$ & $(0.00059)$ & $(0.0029)$ \\
\hline \multirow[t]{2}{*}{ BG } & -0.062 & 0.042 & 0.072 & -0.11 & -0.024 & 0.14 \\
\hline & $(0.004)$ & $(0.0017)$ & $(0.0049)$ & $(0.0078)$ & $(0.0011)$ & (0.0099) \\
\hline \multirow[t]{2}{*}{ CY } & -0.029 & 0.015 & 0.054 & -0.039 & -0.0097 & 0.068 \\
\hline & $(0.0025)$ & $(0.0013)$ & $(0.0034)$ & $(0.0042)$ & $(0.00088)$ & $(0.0053)$ \\
\hline \multirow[t]{2}{*}{$\mathrm{CZ}$} & -0.035 & 0.024 & 0.045 & -0.054 & -0.012 & 0.074 \\
\hline & $(0.00071)$ & $(0.00048)$ & $(0.001)$ & $(0.0012)$ & $(0.00022)$ & (0.0017) \\
\hline \multirow[t]{2}{*}{ DK } & -0.023 & 0.035 & 0.019 & -0.031 & -0.018 & 0.034 \\
\hline & $(0.0018)$ & $(0.00083)$ & $(0.0021)$ & $(0.0023)$ & $(0.00049)$ & $(0.0041)$ \\
\hline \multirow[t]{2}{*}{$\mathrm{EE}$} & -0.056 & 0.039 & 0.074 & -0.08 & -0.021 & 0.12 \\
\hline & $(0.0016)$ & $(0.00091)$ & $(0.0023)$ & $(0.003)$ & $(0.0006)$ & $(0.0041)$ \\
\hline \multirow[t]{2}{*}{ ES } & -0.034 & 0.062 & 0.04 & -0.04 & -0.035 & 0.065 \\
\hline & $(0.00081)$ & $(0.00058)$ & $(0.0013)$ & $(0.0011)$ & $(0.00032)$ & $(0.0021)$ \\
\hline \multirow[t]{2}{*}{ FI } & -0.035 & 0.026 & 0.04 & -0.042 & -0.013 & 0.057 \\
\hline & $(0.0013)$ & $(0.00069)$ & $(0.0021)$ & $(0.0018)$ & $(0.00034)$ & $(0.0028)$ \\
\hline \multirow[t]{2}{*}{ FR } & -0.055 & 0.046 & 0.068 & -0.086 & -0.023 & 0.12 \\
\hline & $(0.0035)$ & $(0.0024)$ & $(0.0045)$ & $(0.0068)$ & $(0.0012)$ & $(0.0085)$ \\
\hline \multirow[t]{2}{*}{$\mathrm{HU}$} & -0.053 & 0.054 & 0.075 & -0.095 & -0.025 & 0.14 \\
\hline & $(0.0022)$ & $(0.0015)$ & $(0.0029)$ & $(0.0048)$ & $(0.00079)$ & $(0.006)$ \\
\hline \multirow[t]{2}{*}{ IS } & -0.085 & 0.056 & 0.12 & -0.2 & -0.02 & 0.26 \\
\hline & $(0.012)$ & $(0.0055)$ & $(0.014)$ & $(0.037)$ & $(0.0028)$ & $(0.038)$ \\
\hline \multirow[t]{2}{*}{ IT } & -0.029 & 0.038 & 0.04 & -0.033 & -0.023 & 0.057 \\
\hline & $(0.00058)$ & $(0.00038)$ & $(0.00097)$ & $(0.00076)$ & $(0.00021)$ & $(0.0014)$ \\
\hline \multirow[t]{2}{*}{$\mathrm{LT}$} & -0.073 & 0.03 & 0.1 & -0.099 & -0.017 & 0.14 \\
\hline & $(0.002)$ & $(0.0011)$ & $(0.0031)$ & $(0.003)$ & $(0.00059)$ & $(0.0042)$ \\
\hline \multirow[t]{2}{*}{ LV } & -0.1 & 0.058 & 0.13 & -0.14 & -0.032 & 0.21 \\
\hline & $(0.0025)$ & $(0.0018)$ & $(0.0035)$ & $(0.0046)$ & $(0.00091)$ & $(0.0061)$ \\
\hline \multirow[t]{2}{*}{ MT } & -0.025 & 0.041 & 0.037 & -0.04 & -0.022 & 0.065 \\
\hline & $(0.0025)$ & $(0.0019)$ & $(0.004)$ & $(0.0039)$ & $(0.001)$ & (0.0063) \\
\hline \multirow[t]{2}{*}{ NL } & -0.037 & 0.035 & 0.048 & -0.057 & -0.016 & 0.077 \\
\hline & $(0.0022)$ & $(0.0012)$ & $(0.0034)$ & $(0.0042)$ & $(0.00072)$ & $(0.0062)$ \\
\hline \multirow[t]{2}{*}{ NO } & -0.03 & 0.033 & 0.061 & -0.056 & -0.018 & 0.093 \\
\hline & $(0.0051)$ & $(0.0024)$ & $(0.0072)$ & $(0.0088)$ & $(0.0011)$ & $(0.011)$ \\
\hline \multirow[t]{2}{*}{ PL } & -0.084 & 0.047 & 0.11 & -0.16 & -0.022 & 0.21 \\
\hline & $(0.0025)$ & $(0.0012)$ & $(0.003)$ & $(0.0062)$ & $(0.00064)$ & (0.0066) \\
\hline
\end{tabular}


Table 4 continued

\begin{tabular}{|c|c|c|c|c|c|c|}
\hline \multirow[t]{2}{*}{ Country } & \multicolumn{3}{|c|}{$(\alpha=2, \beta=1)$} & \multicolumn{3}{|c|}{$(\alpha=2, \beta=3)$} \\
\hline & $\bar{I}$ & $R$ & $P G$ & $\bar{I}$ & $R$ & $P G$ \\
\hline \multirow[t]{2}{*}{ PT } & -0.024 & 0.027 & 0.046 & -0.03 & -0.016 & 0.06 \\
\hline & $(0.0017)$ & $(0.0011)$ & $(0.0031)$ & $(0.0023)$ & $(0.00055)$ & $(0.0039)$ \\
\hline \multirow[t]{2}{*}{ SE } & -0.027 & 0.024 & 0.036 & -0.035 & -0.015 & 0.049 \\
\hline & $(0.0055)$ & $(0.0038)$ & $(0.0086)$ & $(0.0077)$ & $(0.002)$ & $(0.013)$ \\
\hline \multirow[t]{2}{*}{ SI } & -0.018 & 0.012 & 0.034 & -0.023 & -0.0078 & 0.042 \\
\hline & $(0.00063)$ & $(0.0003)$ & $(0.0011)$ & $(0.00086)$ & $(0.0002)$ & $(0.0014)$ \\
\hline \multirow[t]{2}{*}{ UK } & -0.017 & 0.05 & 0.031 & -0.019 & -0.028 & 0.051 \\
\hline & $(0.0018)$ & $(0.0017)$ & $(0.0028)$ & $(0.0023)$ & $(0.00091)$ & $(0.0049)$ \\
\hline
\end{tabular}

Authors' calculations based on EU-SILC. Bootstrapped standard errors in parentheses (200 replications)

(a)

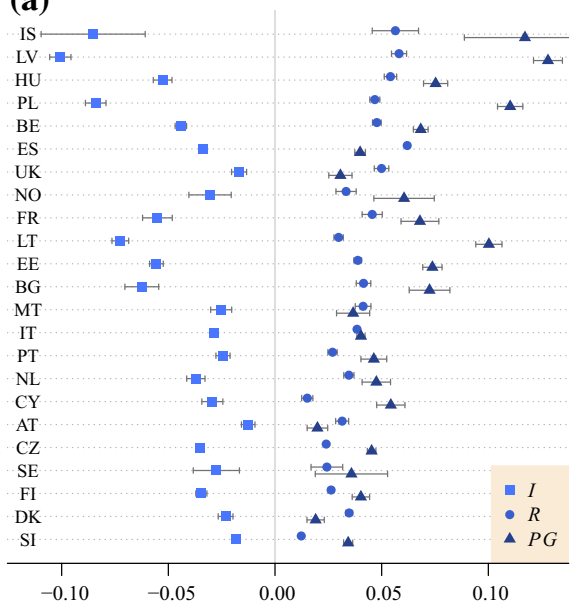

(b)

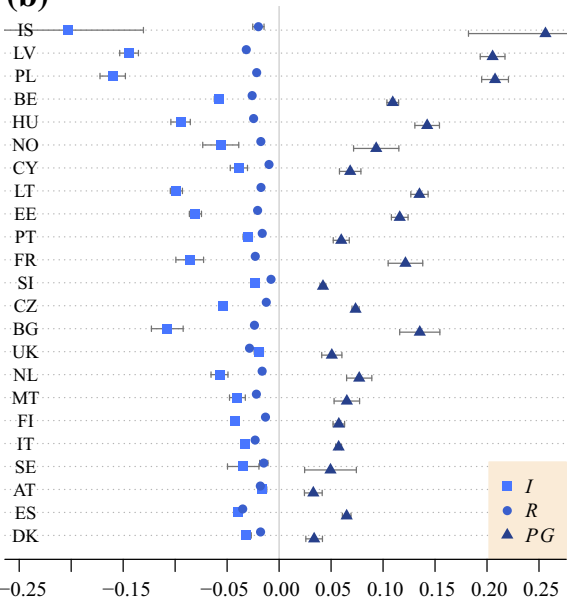

Fig. $8 I P P$ decomposition into inequality $(I)$, reranking $(R)$ and pure growth $(P G)$ effects for 23 European countries, 2006-2007-2008-2009. a $\alpha=2, \beta=1$. b $\alpha=2, \beta=3$. Authors' calculations based on EU-SILC. Whiskers show the 95\% confidence interval (bootstrap with 200 replications)

anti-poorness. Most of that result is however due to the anonymous impact of growth. When the effects of mobility and variability are taken into account, the overall pro-poor judgement is reversed in many cases.

\section{Conclusion}

When is growth pro-poor? This paper argues that a comprehensive assessment of pro-poorness may benefit from a shift from a purely cross-sectional perspective to a longitudinal one, thus accounting for individual poverty dynamics over time. To this end, the paper proposes a family of aggregate indices of intertemporal pro-poorness. In contrast to previous work that compares initial and final distributions of income, this paper makes use of the full information provided by the joint distribution of 
income. The proposed indices aggregate equally-distributed-equivalent measures of the temporal poverty experienced by each individual in a society. The indices capture both the cost of variability and the benefit of intertemporal equalization induced by mobility. Three decomposition procedures show the effect of pure growth, crosssectional inequality, intertemporal inequality, reranking and temporal variability in explaining intertemporal growth pro-poorness. An additional decomposition is also proposed to identify the contribution of separate subperiods.

An empirical illustration of the measurement framework for 23 European countries is also provided. It shows that, unless we impose extreme aversion to temporal variability in poverty gaps, growth can be regarded as pro-poor over the 2006-2009 period in most European countries. The results further show that the intertemporal pro-poorness features of the income transformations that took place over 2006-2009 vary considerably across European countries. They also vary within each country, depending on the normative importance given to intertemporal individual poverty variability versus inter-individual inequality. Thus, mobility, through variability and inequality effects, can change significantly one's assessment of growth pro-poorness and can also help provide a more complete picture of the impact of growth on poverty.

Acknowledgements We are very grateful to Philippe Van Kerm, Robert Zelli, two anonymous referees and the editor for helpful suggestions and comments. This work was supported by the Agence Nationale de la Recherche of the French government through the program "Investissements d'avenir" ANR-10LABX-14-01, as well as by the Fonds National de La Recherche Luxembourg, SSHRC, FRQSC and by the Partnership for Economic Policy (PEP), which is financed by the Government of Canada through the International Development Research Centre and the Canadian International Development Agency, and by the UK Department for International Department and the Australian Agency for International Development.

\section{Appendix}

\section{Generalization to $T$ periods}

As mentioned in the main text, the decompositions provided in this paper can be generalized to time horizons of $T>2$ periods (Fig. 9).

The first decomposition is obtained by adding and subtracting in (16) the EDE of periodic individual poverty as follows:

$$
\underbrace{\Pi_{\alpha}\left(g_{1}\right)-\Pi_{\alpha}(g)}_{A G}+\underbrace{\Pi_{\alpha}(g)-\Pi_{\alpha, \beta}(g)}_{M} .
$$

When $T>2$, the third decomposition can be obtained as :

$$
\begin{gathered}
\underbrace{\left[\Pi_{\alpha, \beta}\left(\boldsymbol{g}_{1}\right)-\Pi_{\alpha, \beta}\left(\boldsymbol{g}_{1}^{I}\right)\right]}_{I}+\underbrace{\left[\Pi_{\alpha, \beta}\left(\boldsymbol{g}_{1}^{I}\right)-\Pi_{\alpha, \beta}\left(\boldsymbol{g}_{1}^{I R}\right)\right]}_{R} \\
+\underbrace{\left[\Pi_{\alpha, \beta}\left(\boldsymbol{g}_{1}^{I R}\right)-\Pi_{\alpha, \beta}(\boldsymbol{g})\right]}_{P G}
\end{gathered}
$$




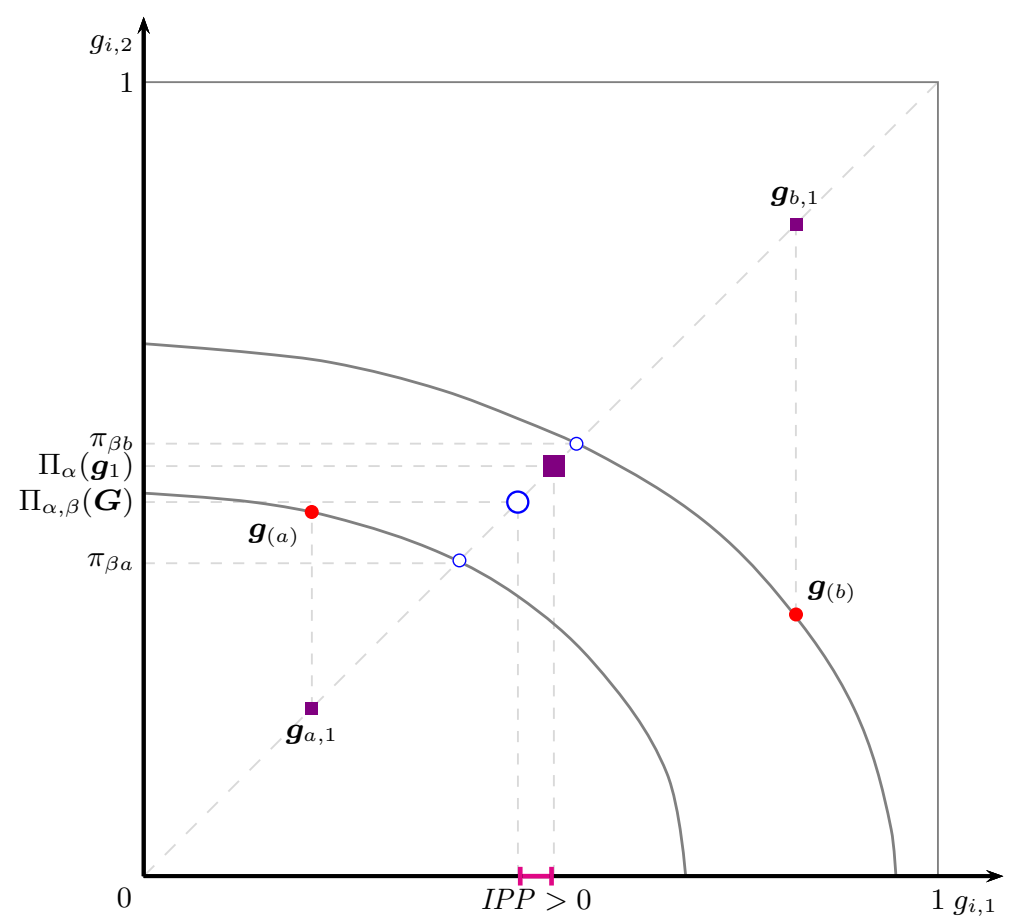

Fig. 9 The intertemporal pro-poorness of a two-period growth/mobility process. The iso-poverty contours correspond to the case of $\beta=2, \omega_{1}=\frac{1}{3}$, and $\omega_{2}=\frac{2}{3}$. For social aggregation, $\alpha$ is set equal to 1

Here, $\boldsymbol{g}^{I}=\left(\boldsymbol{g}_{1}, \ldots, \boldsymbol{g}_{t}^{I}, \ldots, \boldsymbol{g}_{T}^{I}\right)$, where $\boldsymbol{g}_{t}^{I}$ denotes the counterfactual distribution of poverty gaps at time $t$ obtained by preserving the same average poverty gaps and ranks as observed in the first-period distribution. Similarly, $\boldsymbol{g}^{I R}=\left(\boldsymbol{g}_{1}, \ldots, \boldsymbol{g}_{t}^{I R}, \ldots, \boldsymbol{g}_{T}^{I R}\right)$, where $\boldsymbol{g}_{t}^{I R}$ denotes the counterfactual time-specific distribution of poverty gaps obtained by keeping the same average poverty gap as that of the first period distribution.

\section{References}

Alkire S, Foster J (2011) Understandings and misunderstandings of multidimensional poverty measurement. J Econ Inequal 9:289-314

Atkinson A (1970) On the measurement of inequality. J Econ Theory 2:244-263

Atkinson A (2003) Multidimensional deprivation: contrasting social welfare and counting approaches. J Econ Inequal 1:51-65

Atkinson A, Bourguignon F (1982) The comparison of multi-dimensioned distributions of economic status. Rev Econ Stud 49:183-201

Bargain O, Callan T, Doorley K, Keane C (2017) Changes in income distributions and the role of tax-benefit policy during the great recession: an international perspective. Fisc Stud 38:559-585

Bibi S, Duclos J-Y, Araar A (2014) Mobility, taxation and welfare. Soc Choice Welf 42:503-527

Bosmans K, Decancq K, Ooghe E (2015) What do normative indices of multidimensional inequality really measure? J Public Econ 130:94-104

Bossert W, Chakravarty S, d'Ambrosio C (2012) Poverty and time. J Econ Inequal 10:145-162 
Bourguignon F (1999) Comment on multidimensioned approaches to welfare analysis. In: Maasoumi E, Silber J (eds) Handbook of income inequality measurement. Oxford University Press, Oxford

Bourguignon Fr (2011) Non-anonymous growth incidence curves, income mobility and social welfare dominance. J Econ Inequal 9:605-627

Bresson F, Duclos J-Y (2015) Intertemporal poverty comparisons. Soc Choice Welf 44:567-616

Busetta A, Mendola D (2012) The importance of consecutive spells of poverty: a path-dependent index of longitudinal poverty. Rev Income Wealth 58:355-374

Callan T, Nolan B, Walsh J (2011) The economic crisis, public sector pay and the income distribution. In who loses in the downturn? Economic crisis, employment and income distribution. Emerald Group Publishing Limited, Bingley, pp 207-225

Calvo C, Dercon S (2009) Chronic poverty and all that: the measurement of poverty over time. In: Addison T, Hulme D, Kanbur R (eds) Poverty dynamics: interdisciplinary perspectives, chap. 2. Oxford University Press, Oxford, pp 29-58

Canto O, Gradín C, del Rio C (2012) Measuring poverty accounting for time. Rev Income Wealth 58:330354

Chakravarty S (1983a) Ethically flexible measures of poverty. Can J Econ Revue Canadienne d'Économique $16: 74-85$

Chakravarty S (1983b) A new index of poverty. Math Soc Sci 6:307-313

Chakravarty S, Dutta B, Weymark J (1985) Ethical indices of income mobility. Soc Choice Welf 2:1-21

Creedy J, Wilhelm M (2002) Income mobility, inequality and social welfare. Aust Econ Pap 41:140-150

Decancq K, Ooghe E (2010) Has the world moved forward? A robust multidimensional evaluation. Econ Lett 107:266-269

Decanq K, Lugo MA (2012) Inequality of wellbeing: a multidimensional approach. Economica 79:721-746

Duclos J-Y (2009) What is "pro-poor"? Soc Choice Welf 32:37-58

Dutta I, Pattanaik P, Xu Y (2003) On measuring deprivation and the standard of living in a multidimensional framework on the basis of aggregate data. Economica 70:197-221

Dutta I, Roope L, Zank H (2013) On intertemporal poverty measures: the role of affluence and want. Soc Choice Welf 41:741-762

Essama-Nssah B (2005) A unified framework for pro-poor growth analysis. Econ Lett 89:216-221

Essama-Nssah B, Lambert PJ (2009) Measuring pro-poorness: a unifying approach with new results. Rev Income Wealth 55:752-778

Fields GS (2008) Income mobility. In: Blume L, Durlauf S (eds) The new Palgrave dictionary of economics. Palgrave Macmillan, New York, NY

Fields GS (2010) Does income mobility equalize longer-term incomes? New measures of an old concept. J Econ Inequal 8:409-427

Fields G, Ok E (1999) The measurement of income mobility: an introduction to the literature. In: Silber J (ed) Handbook of income inequality measurement, chap. 19. Kluwer Academic Publishers, Dordrecht, pp 557-596

Fortin N, Lemieux T, Firpo S (2011) Decomposition methods in economics. In: Handbook of labor economics, vol 4. Elsevier, pp 1-102

Foster JE (2009) A class of chronic poverty measures. In: Addison T, Hulme D, Kanbur R (eds) Poverty dynamics: interdisciplinary perspectives, chap. 3. Oxford University Press, Kanbur, pp 59-76

Foster J, Rothbaum J (2012) Mobility curves: using cutoffs to measure absolute mobility. Mimeo, George Washington University, Washington

Foster J, Greer J, Thorbecke E (1984) A class of decomposable poverty measures. Econometrica 52:761-766

Friedman M (1962) Capitalism and freedom. University of Chicago Press, Chicago

Gottschalk P, Spolaore E (2002) On the evaluation of economic mobility. Rev Econ Stud 69:191-208

Grimm M (2007) Removing the anonymity asiom in assessing pro-poor growth. J Econ Inequal 5:179-197

Hoy M, Zheng B (2011) Measuring lifetime poverty. J Econ Theory 146:2544-2562

Immervoll H, Peichl A, Tatsiramos K (2011) Who loses in the downturn: economic crisis, employment and income distribution. Emerald Group Publishing

Jäntti M, Jenkins S (2015) Income mobility. In: Atkinson A, Bourguignon F (eds) Handbook of income distribution, chap 10, vol 2. North Holland, New York, pp 807-935

Jäntti M, Kanbur R, Nyyssölä M, Pirttilä J (2014) Poverty and welfare measurement on the basis of prospect theory. Rev Income Wealth 60:182-205

Jenkins S, Van Kerm P (2011) Trends in individual income growth: measurement methods and British evidence. DP 5510, IZA 
Jenkins SP, Brandolini A, Micklewright J, Nolan B (2012) The great recession and the distribution of household income. OUP, Oxford

Kakwani N, Pernia E (2000) What is pro-poor growth? Asian Dev Rev 18:1-16

Kakwani N, Son H (2003) Pro-poor growth: concepts and measurement with country case studies. Pak Dev Rev 42:417-444

Makdissi P, Wodon Q (2003) Risk-adjusted measures of wage inequality and safety nets. Econ Bull 9:1-10

Matsaganis M, Leventi C (2014) Distributive effects of the crisis and austerity in seven EU countries. ImPRovE Working Pape, 14/04

OECD (2015) In it together: why less inequality benefits all. OECD Publishing, Paris

Palmisano F, Peragine V (2015) The distributional incidence of growth: a social welfare approach. Rev Income Wealth 61:440-464

Palmisano F, Van de gaer D (2016) History dependent growth incidence: a characterisation and an application to the economic crisis in Italy. Oxf Econ Pap 68:585-603

Ravallion M, Chen S (2003) Measuring pro-poor growth. Econ Lett 78:93-99

Rohde N, Tang K, Osberg L, Rao D (2017) Is it vulnerability or economic insecurity that matters for health? J Econ Behav Organ 134:307-319

Ruiz-Castillo J (2004) The measurement of structural and exchange mobility. J Econ Inequal 2:219-228

Shorrocks A (2013) Decomposition procedures for distributional analysis: a unified framework based on the Shapley value. J Econ Inequal 11:99-126

Son HH (2004) A note on pro-poor growth. Econ Lett 82:307-314

Western B, Bloome D, Sosnaud B, Tach L (2012) Economic insecurity and social stratification. Annu Rev Sociol 38:341-359

Zheng B (2012) Measuring chronic poverty: a gravitational approach. Working paper, University of Colorado Denver 